\title{
Microbiota promotes chronic pulmonary inflammation by enhancing IL-17A and autoantibodies
}

Koshika Yadava ${ }^{1,2 *}$, Céline Pattaroni ${ }^{1}$, Anke K. Sichelstiel ${ }^{1}$, Aurélien Trompette ${ }^{1}$, Eva S. Gollwitzer $^{1}$, Olawale Salami ${ }^{1}$, Christophe von Garnier ${ }^{3}$, Laurent P. Nicod ${ }^{1}$, Benjamin J. $\operatorname{Marsland}^{1 *}$

${ }^{1}$ Service de Pneumologie, Faculty of Biology and Medicine, CHUV-UNIL, Lausanne, Switzerland.

2 Department of Medicine, Division of Infectious Diseases, Stanford University School of Medicine, Stanford, California, USA

${ }^{3}$ Department of Respiratory Medicine, Inselspital, Bern University Hospital and Department of Clinical Research, University of Bern, Bern, Switzerland

*Corresponding authors: Benjamin Marsland, Service de Pneumologie, CLE D02-206, Chemin des Boveresses 155 - CH-1066 Epalinges, Switzerland. EMAIL: benjamin.marsland@chuv.ch, TEL: 004121 3141378, FAX: 004121 3141395. Koshika Yadava, Department of Medicine, Division of Infectious Diseases, Stanford University School of Medicine, Stanford, California, USA. EMAIL: koshika.yadava@gmail.com

Condensed title: Microbiota sustains chronic pulmonary inflammation.

Word count: 4809 


\section{Author contributions:}

Conceived and designed the experiments: KY, BJM. Performed the experiments and analyzed data: KY, AS, AT, OS, EG, CP, BJM. Prepared the manuscript: KY, BJM, LPN, CVG.

This work was funded by the Swiss National Science foundation grant CRSII3_141875 awarded

to B.J.M and C.vG. KY is a currently funded by the Swiss National Science foundation early postdoc mobility grant. The authors declare no conflict of interest. 


\begin{abstract}
:
Rationale: Changes in the pulmonary microbiota are associated with progressive respiratory diseases including chronic obstructive pulmonary disease. Whether there is a causal relationship between these changes and disease progression remains unknown.
\end{abstract}

Objective: To investigate the link between an altered microbiota and disease, we utilized a murine model of chronic lung inflammation that is characterized by key pathological features found in COPD and compared responses in specific pathogen free (SPF) mice and mice depleted of microbiota by antibiotic treatment or devoid of a microbiota (axenic).

Methods: Mice were challenged with LPS/elastase intranasally over 4 weeks, resulting in a chronically inflamed and damaged lung. The ensuing cellular infiltration, histological damage and decline in lung function were quantified.

Measurements and Main results: Similar to human disease, the composition of the pulmonary microbiota was altered in diseased animals. We found that the microbiota richness and diversity were decreased in LPS/Elastase-treated mice, with an increased representation of the genera Pseudomonas, Lactobacillus and a reduction in Prevotella. Moreover, the microbiota was implicated in disease development as mice depleted, or devoid, of microbiota exhibited an improvement in lung function, reduced inflammation and lymphoid neogenesis. The absence of microbial cues markedly decreased the production of IL-17A, whilst intranasal transfer of fluid enriched with the pulmonary microbiota isolated from diseased mice enhanced IL-17A production in the lungs of antibiotic treated or axenic recipients. Finally, in mice harboring a microbiota, neutralizing IL-17A dampened inflammation and restored lung function. 
Conclusions: Collectively, our data indicate that host-microbial cross-talk promotes inflammation and could underlie the chronicity of inflammatory lung diseases. 


\section{Introduction}

The rise in the prevalence of chronic obstructive pulmonary disease (COPD) is a global health concern(1). Exposure to cigarette smoke is the most widely associated environmental risk factor for the development of the disease(2), which presents as chronic bronchitis and emphysema that lead to progressive and irreversible airflow limitation $(3,4)$. While patients can manifest mild to severe disease, as defined by the degree of airflow obstruction, the signals leading to increased severity and progression remain unclear $(3,5)$. In spite of the heterogeneity in human disease, it is apparent that aberrant inflammatory responses substantially contribute to the decline in lung function (5-7).

Intriguingly, not all people exposed to similar levels of cigarette smoke develop the disease (3). Moreover whilst smoking cessation does lead to an improvement in lung function in moderate disease, in some cases it does not impact on disease progression (8). One could speculate that although environmental triggers enhance the disease, in susceptible individuals the established disease can progress through a self-sustained inflammatory cycle. Given the limitations of current therapies to arrest COPD progression, it is important to identify the factors that can facilitate the establishment of the chronic inflammatory pathways and favor the disease. One such factor could be the microbiota. Previously considered sterile, breakthroughs in non-culture based detection methods have provided evidence that the respiratory tract harbors a microbiota (9-18). Notably, the microbiota in the respiratory tract of healthy volunteers, smokers without COPD and patients with severe disease are distinct $(9,10,12-14)$. Though microbial dysbiosis has been shown to increase susceptibility to chronic diseases such as inflammatory bowel disease (IBD)(19, 20), it is currently unknown whether such a phenomenon contributes to COPD. 
Another emerging hypothesis suggests there is an autoimmune component driving the progression of $\operatorname{COPD}(5,21,22)$. Though controversial, there is both circumstantial and direct evidence implicating autoimmune mechanisms in COPD pathogenesis $(5,21,22)$. Lymphoid follicles play a pathological role in several autoimmune diseases by mediating the generation of self-reactive antibodies(23). While lymphoid follicles themselves have been consistently observed in both animal models and humans with COPD (24-27), there are conflicting reports regarding the production of self-reactive antibodies (28-32), thus the autoimmune concept of COPD remains open and might reflect a subtype of the disease. Incidentally, cues from the microbiota have been reported to support lymphoid neogenesis(33), the production of self reactive antibodies (34) and are implicated in the pathogenesis of a variety of autoimmune models (34-36). Whether there could be a similar link between the pulmonary microbiota and autoimmune mechanisms in COPD is yet to be established.

We aimed to elucidate the role of the microbiome in COPD using a murine model(37), which mimics key features of human disease. We found that akin to what has been seen in humans, the airway microbiota differs between healthy and diseased mouse lungs. We report that the microbiota has functional implications as in its absence disease development is abrogated. 


\section{Materials and methods}

Mice: BALB/c mice were purchased from Charles River, l'Arbresele, Cedex, France. All animal experiments were performed according to institutional guidelines and Swiss federal and cantonal laws on animal protection.

Model of chronic pulmonary inflammation: Mice were exposed intranasally to a mixture of $7 \mathrm{ug}$ LPS from E. coli O26:B6 (Sigma-Aldrich) and 1.2 U porcine pancreatic elastase (elastin products company) in $100 \mathrm{ul}$ once a week for over 4 weeks. Terminal readout was carried out one week after the last challenge.

Assessment of pulmonary lung function: Lung compliance and FEV/FVC parameters were measured by Snapshot and NPFE perturbations using the FlexiVent invasive airway mechanics system from Scireq. Mice were anesthetized by administering $100 \mathrm{mg} / \mathrm{kg}$ ketamine (Ketasol-100, Graeub) intramuscularly and of $50 \mathrm{mg} / \mathrm{kg}$ pentobarbital (Esconarkon, Streuli Pharma) intraperitoneally. Subsequently, mice were tracheotomized and mechanically ventilated at a rate of $450 \mathrm{breaths} / \mathrm{min}$ and a tidal volume of $10 \mathrm{ml} / \mathrm{kg}$ bodyweight.

Antibiotic treatment: For depleting microbiota prior to the start of experiment mice were given 10\% Enrofloxacin (Baytril) in drinking water for 2 weeks followed by amoxycillin/clavulanic acid (Coamoxy-mepha) in the drinking water for another 2 weeks. During the course of the experiment mice were maintained on Coamoxy-mepha treatment.

\section{$16 S$ rDNA preparation from BALF and sequencing}

Broncho-alveolar lavage was performed in $1 \mathrm{ml}$ volume of sterile PBS and collected in a $2 \mathrm{ml}$ Biopure tube (Eppendorf). Negative control was obtained by flushing $1 \mathrm{ml}$ of sterile PBS into the BAL tubing system and processed identically to the mouse BALF samples. BALF were directly centrifuged at $14,000 \mathrm{xg}$ for $4 \mathrm{~min}$ at $4^{\circ} \mathrm{C}$ and processed in sterile conditions under a laminar flow 
hood. Pellets were incubated with $9000 \mathrm{U}$ of Ready-Lyse Lysozyme (Epicentre) for $1 \mathrm{hr}$ at $37^{\circ} \mathrm{C}$. 20ul of proteinase K in 200ul AL buffer (QIAamp DNA Mini Kit) was then added to the solution and incubated for $30 \mathrm{~min}$ at $56^{\circ} \mathrm{C}$ with shaking. After this step, BALF from 4 mice coming from 2 different cages were pooled and further processed with QIAmp DNA Mini Kit, according to the manufacturer's protocol. DNA was eluted in 30ul DNAse/RNAse-free water (Sigma). PCR for the $16 \mathrm{~S}$ rDNA library preparation was performed using modified $27 \mathrm{~F}$ and $338 \mathrm{R}$ universal primers, which target the V1-V2 hypervariable region of the 16S rDNA gene. Primers were as follows:

$27 \mathrm{~F}-5$

AATGATACGGCGACCACCGAGATCTACACTATGGTAATTCCAGMGTTYGATYMTGGC TCAG-3' and 338R-5'CAAGCAGAAGACGGCATACGAGATNNNNNNNNNNNN $A G T C A G T C A G A A G C T G C C T C$ CCGTAGGAGT-3'

where Illumina adaptor sequences are bold, linkers italicized and NNNNNNNNNNNN sequences represents the sample-specific MID tag barcodes. The temperature cycles were set as follows: 3 minutes of initial denaturation at $94^{\circ} \mathrm{C}$, repeated steps of 30 seconds denaturation at $94{ }^{\mathrm{O}} \mathrm{C}, 30$ seconds of annealing at $56{ }^{\mathrm{O}} \mathrm{C}, 1.3$ minutes extension at $72{ }^{\mathrm{O}} \mathrm{C}$ and a final step of 5 minutes at $72{ }^{\circ} \mathrm{C}$. PCR reactions were performed in triplicates and one additional PCR negative control without DNA template was added for each reaction. Each reaction consisted of 8ul of DNA template, $0.44 \mathrm{ul}$ of each $27 \mathrm{~F}$ and $338 \mathrm{R}$ primers at $10 \mathrm{mM}, 2 \mathrm{ul}$ of AccuPrime buffer II, 0.09ul of AccuPrime Taq DNA polymerase high fidelity (Invitrogen) and DNAse/RNAse-free water (Sigma) to reach a total volume of 20ul. After amplification, PCR product triplicates were 
pooled before visualization on a $1.5 \%$ agarose gel. The bands of the specific size (approximately 300bp) were cut and purified with QIAquick gel extraction kit (Qiagen). Recovered DNA was then quantified using the Quant-iT PicoGreen ds assay (Life Technologies) and amplicons were pooled in a single tube in equimolar amounts. Sequencing was performed on an Illumina MiSeq platform using MiSeq reagent kit V2-500 (pair-end, 2x250).

\section{$16 S$ rDNA sequencing analysis}

Sequences obtained were processed and analyzed using Quantitative Insights Into Microbial Ecology (QIIME, v.1.8.0) software(38). Paired forward and reverse reads were merged using fastq-join, demultiplexed, and quality filtered (quality Phred score $\mathrm{Q}>20,<3$ low quality base calls). Operational taxonomic units (OTUs) were assigned using an open reference picking strategy with Uclust(39) at $97 \%$ identity against the $97 \%$ Greengenes reference database (v13.8)(40). Alpha diversity rarefaction curves for chaol and Shannon indexes were calculated in QIIME using 10 iterations represented as mean+SD at different sequencing depths $(2,000-$ 98,000). All downstream analyses were performed using a rarefied OTU table at 40,000 sequencing depth. A heatmap displaying the OTUs represented at more than $0.05 \%$ relative abundance in a minimum of 2 samples was created using the heatmap. 2 function of the gplots package in $\mathrm{R}(41)$. The dendrogram was generated using Ward's hierarchical clustering with hclust algorithm in R on Bray-Curtis dissimilarity matrix calculated in QIIME.

Preparation and transfer of microbiota-enriched BAL fluid: For preparing the microbiotaenriched BAL fluid, BAL was performed 3 times using 1ml of PBS per mouse. 5 mice were pooled per group. The BAL was then centrifuged at $2000 \mathrm{rpm}$ for 10 minutes at 4 degrees and 
the pellet containing mouse cells was discarded. The BAL supernatant was aliquoted into biopur tubes and centrifuged at $14000 \mathrm{~g}$ for 10 minutes at 4 degrees and washed with PBS at the same speed. The final pellet was snap frozen in liquid nitrogen and stored at -80 till use. Before intranasal administration each aliquot was resuspended in $2 \mathrm{mls}$ of PBS and administered to recipient mice in a volume of $100 \mathrm{ul}$ per mouse intranasally.

Neutralization of IL-17A: For neutralization of IL-17A, mice were treated with 250 ug of antiIL-17A (clone 17F3) or the corresponding isotype control antibody (clone MPOC-21) from BioXCell. Antibodies were administered intraperitoneally on days 6,10,13,17,20,24 days after the first challenge of LPS/elastase challenge.

Results

Murine model of chronic pulmonary inflammation mimics key pathological features of human disease

To study the underlying pathogenic mechanisms of COPD we utilized a murine model of chronic pulmonary inflammation (Figure 1A). Mice were treated with a combination of LPS and elastase over 4 weeks. Co-administration of LPS/elastase resulted in an increase in compliance, $(\mathrm{P}<0.05)$ (Figure 1B) and a decrease in the percentage of forced expiratory volume in 0.1 second over forced vital capacity (FEV0.1/FVC), $(\mathrm{P}<0.01)$ (Figure 1C). The decline in lung function was associated with emphysematous changes in the lung parenchyma, quantified by both mean linear intercept and destruction index parameters $(\mathrm{P}<0.001)$ (Figure 1D-F) in addition to peribronchiolar and perivascular infiltration of the lung tissue (Figure 1G). There was also an enhanced cellular infiltration in the broncho-alveolar lavage fluid (BAL) $\mathrm{P}<0.001$ (Figure 1H), with marked increase in macrophages $(\mathrm{P}<0.05)$, neutrophils $(\mathrm{P}<0.05)$ and lymphocytes 
$(\mathrm{P}<0.001)$ (Figure 1I). Notably the emphysema and inflammation persisted at least 2 months after the cessation of LPS/elastase treatment, $\mathrm{P}<0.001$ (Figure E1A-C). Although neutrophilia waned in the BAL, the continued prevalence of hemosiderin-laden macrophages $(\mathrm{P}<0.01)$ was indicative of chronic inflammation and micro-hemorrhaging months after the final challenge (Figure E1D)(42).

Chronic pulmonary inflammation is associated with lymphoid neogenesis, enhanced local antibody responses and $I L-17 A$ production

In line with previous data in human disease and animal models of CS induced emphysema, (24-27), we observed the formation of lymphoid follicles (LFs) which could be categorized as bronchiolar associated (BALT) $(\mathrm{P}<0.01)$, alveolar associated $(\mathrm{ALT})(\mathrm{P}<0.01)$ or vascular (VALT) $(\mathrm{P}<0.001)$ lymphoid tissue base on their localization (Figure 2A). We found that VALT accounted for the majority of LFs. Moreover these LFs persisted even in the absence of inflammatory stimuli in mice that were analyzed 9 weeks after the last challenge $(\mathrm{P}<0.05)$ (Figure E1E). Overall there was an increase in the frequency of germinal center (GC) B cells, $(\mathrm{P}<0.05)$ (Figure 2B) as identified by Gl7 staining and $\mathrm{T}$ follicular helper cells $(\mathrm{Tfh}),(\mathrm{P}<0.01)$ (Figure 2C) as defined by the co-expression of PD-1 and G17, in the lungs of LPS/elastase treated mice. To assess whether the presence of lymphoid follicles correlated with an increase in the local antibody response, we measured the amount of the antibody isotypes $\operatorname{IgG} 1$, IgA and IgM in the BAL of PBS or LPS/elastase treated mice. All isotypes were increased in the BAL of LPS/elastase treated mice, $(\mathrm{P}<0.05)$ (Figure 2D). Of note, no increase in the systemic levels of any isotype was detected (Figure E2A). 
We then investigated the reactivity of these antibodies against collagen and elastin, which constitute a component of the lung tissue breakdown products. A significant increase in specific responses against collagen was detected for $\operatorname{IgG1},(\mathrm{P}<0.01)$ and $\operatorname{IgA}(\mathrm{P}<0.001)$ but not $\operatorname{IgM}$ isotypes (Figure 2E-G). A marked increase in specific antibodies against elastin was observed for IgA $(\mathrm{P}<0.05)$, IgG1 $(\mathrm{P}<0.01)$ and $\operatorname{IgM}(\mathrm{P}<0.05)$ antibody isotypes (Figure 2E-G). We did not detect an increase in systemic levels of elastin specific IgG1 and IgA responses, although collagen specific antibodies were increased (Figure E2 B,C). To further characterize the autoimmune aspect of the disease we enumerated IL-17 producing T cells (Figure $2 \mathrm{H}-\mathrm{K}$ ). We found that IL-17 production by both $\gamma \delta+(\mathrm{P}<0.0001)$ (Figure $2 \mathrm{H})$, and CD4+ T cells $(\mathrm{P}<0.0001)$, was increased in the diseased lungs (Figure 2I). IL-17A production was also induced when sorted $\gamma \delta+($ Figure $2 \mathrm{~J}$ ) and CD4+ T cells (Figure $2 \mathrm{~K}$ ) populations isolated from the lungs of LPS/elastase treated mice were restimulated with collagen or elastin in vitro. Furthermore we found that the protein levels of IL-6 and IL-1 beta, cytokines that can enhance IL-17A responses, in addition to levels of IL-17A itself, were increased in the BAL fluid of LPS/elastase treated animals (Figure E3A-C)

The pulmonary microbiota is altered upon the induction of chronic pulmonary inflammation.

It has been reported that humans with COPD have an altered airway microbiota(10, 13), thus we investigated whether similar changes occurred in our mouse model. We extracted bacterial DNA from BAL of mice treated with PBS or LPS/Elastase over 4 weeks and assessed microbiota diversity and composition by Illumina $16 \mathrm{~S}$ rDNA sequencing using a custom protocol. Indeed, amplifying bacterial DNA from mouse BAL is particularly challenging given the low biomass and subsequent high risk of contamination. For these reasons, we pooled BAL from 4 mice to 
increase the bacterial biomass and we used stringent negative controls where PBS (as used for the BAL) was exposed to the same environment, tubing and extraction kits as the BAL from mice. A negative control, where we successfully found an amplified bacterial 16S rDNA fragment, was included in the sequence analysis in order to allow conclusions to be drawn from low abundance bacterial sequences. We found that microbiota richness and diversity were decreased in the pooled BAL of LPS/Elastase-treated mice, as indicated by chaol richness and Shannon diversity rarefaction curves (Figure 3A). Of note, the Shannon index diversity was higher in the negative control than the LPS/ elastase group, potentially indicative of an increased abundance of certain bacteria in the LPS/ elastase group, which is reflected by the abundance component of the Shannon diversity calculation. We next assessed microbiota composition, with particular attention to the negative control. We observed that the most abundant OTUs present in BAL samples, such as Family Comamonadaceae, Family Flavobacteriacae, and Family Microbacteriaceae were also predominant in the negative control but their relative abundance did not differ among BAL samples (Figure 3B). Importantly, Ward hierarchical clustering algorithm using Bray-Curtis distance efficiently distinguished and clustered BAL samples of the treatments, as compared to the negative control (Figure 3B). These data show that a distinct microbiota was present in healthy airways, diseased airways and the background control. To further investigate the changes in microbiota induced by LPS/Elastase treatment, we excluded contaminant OTUs and assessed the differentially abundant genera across the treatments. We identified 4 genera of particular note: Prevotella, Pseudomonas, Lactobacillus, and Chryseobacterium (Figure 3C). Prevotella was present in the BAL of the PBS control group but absent in the BALF of LPS/Elastase treated mice. On the contrary, relative abundance of Pseudomonas, Lactobacillus and Chryseobacterium was increased in the BAL of LPS/Elastase 
treated mice. Overall, as reported for the human airway microbiota, the airways of mice with this chronic lung disease are characterized by a distinct microbiota to those with healthy airways.

\section{Microbiota derived signals amplify innate and adaptive inflammation in disease}

To investigate whether microbiota dependent signals contribute to the persistent inflammation, we compared responses between SPF mice and mice depleted of a microbiota using an antibiotic treatment regime. Before the start of the experiment mice were given 10\% Baytril in drinking water for 2 weeks followed by treatment with coamoxy-mepha for another 2 weeks. This treatment decreased the microbial load by approximately $6 \log ,(\mathrm{P}<0.0001)$ (Figure E4). During the course of the experiment mice were maintained on coamoxy-mepha treatment. We found that antibiotic treated mice showed no change in FEV0.1/FVC (Figure 4A) but a significant reduction in lung compliance, $(\mathrm{P}<0.05)$ (Figure 4B). This was linked to a decrease in inflammation in the lungs and airways (Figure 4C), decreased total cell counts, $(\mathrm{P}<0.01)$ (Figure 4D) and neutrophil $(\mathrm{P}<0.01)$ and interstitial macrophage $(\mathrm{P}<0.01)$ infiltration in the BAL (Figure 4E,F). Macrophage subsets were identified as described in supplementary Figure E5A. Antibiotic treatment also resulted in a reduction in the frequency of VALT $(\mathrm{P}<0.05)$ (Figure 4G). Though the total antibody levels of IgG1 and IgM in the BAL were unaffected in antibiotic treated mice (Figure 4H), collagen specific IgG1 responses were significantly reduced $(\mathrm{P}<0.01)$ (Figure 4I). Comparatively total $\operatorname{IgA}$ responses were reduced $(\mathrm{P}<0.01)$ (Figure $4 \mathrm{H})$ and in line with this, collagen and elastin specific IgA responses were reduced $(\mathrm{P}<0.05)$ (Figure $4 \mathrm{~J})$.

Microbiota enhances production of IL-17A by T cells 
Microbiota dependent signals have been shown to amplify autoimmune diseases in an IL-17 dependent manner (34-36). Both autoimmune mechanisms and IL-17 (31, 46-54) are implicated in the pathogenesis of COPD. Antibiotic treated mice showed a reduced IL-17A response $(\mathrm{P}<0.05)$ (Figure 5A). Upon investigation of the cellular sources of IL-17A we found no difference in the composition of cells producing IL-17A (Figure 5B) using the gating strategy shown in Figure E5B, and both CD4+ and $\gamma \delta \square$ T cells accounted for the majority of IL-17A producers. However the frequencies of IL-17A+ within CD4+ T cells and the total number of IL$17 \mathrm{~A}+\mathrm{CD} 4+\mathrm{T}$ cells were markedly reduced upon antibiotic treatment $(\mathrm{P}<0.01)$ while only a minor reduction was seen for $\gamma \delta \square$ T cells which was not statistically significant (Figure 5C,D). Similar to antibiotic treated mice, axenic mice exhibited reduced recruitment of neutrophils and macrophages in the airways $(\mathrm{P}<0.05, \mathrm{P}<0.01$ respectively) (Figure E6A-D) and a specific reduction in IL-17A producing $\gamma \delta+\mathrm{T}$ cells $(\mathrm{P}<0.05)$ (Figure $\mathrm{E} 6 \mathrm{E})$.

In an attempt to assess whether the altered microbiota in disease could directly enhance IL-17A responses, we performed a transfer experiment. Antibiotic treated mice were challenged with LPS/elastase on day 0,7 and 21. Concurrently they were given a solution that was enriched for the airway microbiota of PBS or LPS/elastase treated mice intranasally. We found that the transfer of this microbiota-enriched solution from LPS/Elastase treated mice resulted in an increase in the IL-17A producing cells in the lungs of recipient mice (Figure 5E). In particular IL-17A producing CD4+ T cells (Figure 5F) were increased $(\mathrm{P}<0.05)$ while $\gamma \delta+\mathrm{T}$ cells (Figure 5G) were unaffected. Performing the same experiment using axenic recipients we observed an increase in both the proportion of IL-17A producing CD4+ and $\gamma \delta \square \mathrm{T}$ cells $(\mathrm{P}<0.05$ ) (Figure $\mathrm{E} 6 \mathrm{~F})$. 
IL-17A kinetics correlates with disease severity and targeted neutralization of IL-17A ameliorates disease

We next sought to determine the kinetics of IL-17A production during the induction of disease. We modified our existing model to recapitulate different levels of severity similar to COPD in humans. We were able to distinguish mild and severe disease based upon the decline in lung function seen at different timepoints in the disease model (Figure 6A,B). We found that the kinetics of IL-17A production followed the progression of disease (Figure 6C). Moreover both IL-17 producing $\gamma \delta \square \mathrm{T}$ cells and CD4 $+\mathrm{T}$ cells increasingly accumulated in the lungs with repeated LPS/elastase challenges $(\mathrm{P}<0.01)$ (Figure 6D,E, Figure E7). Based on the kinetics observed in mild versus severe disease we performed a targeted neutralization of IL-17A starting one day before the second LPS/elastase challenge (Figure 6F). We found that neutralizing IL17A did not improve FEV0.1/FVC but reduced lung compliance significantly $(\mathrm{P}<0.05)$ (Figure $6 \mathrm{G}, \mathrm{H})$ in addition to the total cellular and neutrophilic infiltration into the $\mathrm{BAL}(\mathrm{P}<0.01)$ (Figure 6I,J). Neutralizing IL-17A also reduced the total frequency of lymphoid follicles $(\mathrm{P}<0.05)$, without specifically affecting any particular subtype (VALT, ALT or BALT) (Figure 6K). This was also associated with a reduction in total $\operatorname{IgG} 1(\mathrm{P}<0.05)$ whilst IgA and $\operatorname{IgM}$ were increased ( $\mathrm{P}<0.05, \mathrm{P}<0.01$ respectively) (Figure 6L). Overall targeting the IL-17A pathway was effective at ameliorating inflammation and uncoupling the autoimmune component of the disease.

\section{Discussion}

Alterations in the gut microbiome have been extensively documented for chronic diseases such as inflammatory bowel disease (IBD) $(19,20)$. Although the gut microbiota can impact upon systemic immune responses, there is an emerging paradigm supporting the importance of host- 
microbe interactions localized within a single habitat, such as that found in the lung and skin (55, 56). Several studies have shown that the composition of the airway microbiota in healthy lungs differs from lungs of patients with COPD, although as yet whether disease creates a habitat for the bacteria, or whether the bacteria cause disease hasn't been delineated $(10,13,14)$. Our findings implicate a functional role for the microbiota in COPD. It is noteworthy that there were many similarities in the types of changes seen in microbial composition in the airways of mice as in humans. Specifically, we found that the overall diversity of the pulmonary microbiome was reduced, Prevotella was absent while the bacterial genera Pseudomonas, Lactobacillus were increased in abundance in the LPS/ Elastase treated animals as compared to controls (43). This correlates with studies in humans, showing that Prevotella is a common colonizer of the airways of healthy subjects, when compared to asthmatic or COPD patients(13, 43). Consistently Pseudomonas is increased in asthmatic and COPD patients(43), and its presence correlates with COPD severity(44). Similarly the relative abundance of Lactobacillus is also increased in asthmatic and COPD patients(43) and an additional study has linked it to COPD severity(10). Chryseobacterium levels were also increased in the BAL of LPS/Elastase treated mice. This did not correlate with any published data in COPD patients, but studies have shown that Chryseobacterium infection in individuals with cystic fibrosis correlates with Pseudomonas (45). A key question still facing the field is where does the airway microbiota originate? (57). Recent studies suggest the pulmonary microbiome originates from the dispersal of microbes from the nasal and oral cavities $(58,59)$. It is possible that this 'seeding' population is altered in COPD patients and this subsequently affects the microbiome in the lungs. Alternatively the state of chronic inflammation in the diseased lungs may provide a selection pressure facilitating colonization by specific bacteria. Considering our experiments were performed under controlled 
conditions with mice housed in isolated and filtered cages, our results support the concept that inflammatory conditions allow the outgrowth of bacteria that are part of the steady-state 'healthy' microbiota.

Increased levels of IL-17A have been implicated in stable COPD (52), and a recent study has shown that the number of CD4+ IL-17A+ cells in the small airways positively correlates with airflow limitation (46). Tracking the development of disease progression in our model showed that IL-17A production increased with disease severity. Moreover we observed temporal changes in the cellular sources of IL-17A (Figure E7). We found that $\gamma \delta \square \mathrm{T}$ cells accounted for the majority of the few IL-17A producing cells in the healthy and mildly diseased lungs. In severe disease there was an expansion of both IL-17A producing CD4+ and $\gamma \delta \square$ T cells. Signals from commensal bacteria have been shown to enhance the expansion of both $\gamma \delta+\mathrm{T}$ cells as well as Th17 cells (34, 60-62) and exacerbating IL-17 mediated inflammation in experimental autoimmune encephalitis (EAE) and arthritis (34-36). In particular, specific bacteria can induce Th17 responses amongst which segmented filamentous bacteria (SFB) have been extensively studied $(34,36)$. Although SFB were not detected in the lung in our study, it is likely that the outgrowth of other lung bacteria resident in the diseased lungs could also promote IL-17 responses. In the current study, we attempted to transfer the microbiota from the BAL of either PBS or LPS/elastase treated mice into the airways of mice depleted (with antibiotics) or devoid (germ-free) of a microbiota. This transfer consisted of a microbial pellet that had been isolated (excluding host cells and soluble components in suspension) from the BAL performed on mice, however in addition to the enriched microbial components of this pellet, acellular material from the lungs could also have been enriched. Transfer of the microbiota-enriched solution derived from mice that had previously been treated with LPS/ elastase, increased the production of IL-17 
in recipient mice, as compared to the solution derived from mice previously treated with PBS. Whether this experimental approach led to a sufficiently large increase in IL-17 levels to influence lung function remains to be determined. There are several technical limitations to the experimental approach of transferring the airway microbiota. For instance, it is unclear whether viable bacteria are required to see this effect. Another important caveat is we are unable to distinguish between the influence of the microbes and that of other potential constituents of the processed BAL fluid, for example cellular debris. With the current state-of-the-art, and the very low bacterial biomass in the airways of mice, we are limited with feasible approaches to address this point. As such, from this study we can only conclude the microbiota changes in the airways of mice treated with LPS/ Elastase, similar to that reported in humans; depletion (antibiotics) or absence (axenic/ germ-free mice) of a microbiota ameliorates disease; and transfer of a microbially-enriched fraction of the BAL from diseased animals increases the disease-causing IL-17 inflammatory pathway in recipient mice. A further possibility is that the role of the microbiota in promoting disease in our model is due to the gut microbiota, indeed, we have previously reported a gut-lung axis with mice fed a high fiber diet being protected against allergic airway inflammation(63). However, in the current study we expect the airway microbiota to play a more fundamental role as we did not find changes in the gut microbiota in our model (data not shown). It remains possible that certain changes in the gut microbiota could impact upon the development of COPD, and future in-depth metagenomic approaches could provide the answer.

Concurrent with the development of the IL-17 response in our model, we found an autoimmune component of the inflammation evolved. It is tempting to speculate that the microbiallyenhanced IL-17 response promotes an autoimmune component, that further perpetuates the 
disease. The increased availability of self-antigens due to the destruction of lung tissue might also allow the expansion of auto-reactive T cells. Further supporting an autoimmune component to disease pathogenesis, lymphoid follicles have consistently been observed in animal models and in humans with COPD (24-27). Recently Bracke et al demonstrated a pathogenic role of LFs in disease (26). In this study they abrogated LF formation by targeting CXCL13 and observed a decrease in the local antibody response with a concomitant improvement in specific aspects of disease such as inflammation and alveolar wall destruction. Microbial colonization and infections are more frequent in patients with very severe disease. From an evolutionary standpoint, LFs in chronic lung diseases might arise to combat infections by enhancing the local immune response. However self-antigens derived from the collateral damage of the lung tissue might also be presented within LFs and result in the production of autoantibodies $(22,64)$. While sequence analysis of B cell clones isolated from LFs in COPD lungs has indicated the presence of an oligoclonal, antigen specific humoral response (25), there are conflicting reports regarding the production of self-reactive antibodies (28-32). It is important to note that most of these studies assess systemic antibody levels, which may not be representative of responses within the lung. Another caveat in these studies is the identification of the relevant autoantigen, which may vary considerably amongst patients. In our model and in the CS-induced model of emphysema, LF formation is associated with an increase in local antibodies levels in the BAL while systemic antibodies were unaffected $(25,26)$. In line with this data, the deposition of $\operatorname{IgG}$ complexes has been demonstrated in lungs of patients with severe COPD, although their antigenic specificity is unknown $(30,65)$. A limitation of our study is that we investigated self-reactive antibodies to only 2 self-antigens: collagen and elastin, which constitute only a portion of the breakdown products of the lung tissue. In the future it would be valuable to comprehensively characterize 
the repertoire of the self-reactive antibodies in COPD patients and investigate whether specific antibody signatures are correlated with disease severity. This could distinguish a subset of COPD patients in whom disease pathogenesis has a clear association with autoimmunity and ultimately identify patients that would benefit the most from treatments targeting B cells $(66,67)$.

The beneficial versus detrimental role of local antibody responses could be determined by different antigen specificities and associated isotypes. It has been reported that compared to COPD patients, healthy smokers exhibit a preferential switching to $\operatorname{IgA}(68)$. $\operatorname{Ig}$ A responses at mucosal surfaces are associated with protective immunity, and blunted IgA responses in COPD can be linked to increased susceptibility to infections (69). Conversely self-reactive antibodies, in particular IgG1 isotypes, are more prevalent in severe disease and implicated in pathogenesis $(30,65,68)$. In our study, depleting the microbiota had a profound affect on the total IgA levels suggesting that a proportion of these antibody responses may be directed against the microbiota. However the absence of a microbiota also reduced the levels of self-reactive IgA and IgG1 antibodies. Whether this is due to the cross reactivity between microbial and self-antigens or an indirect effect by the induction of IL-17, as seen in a model of autoimmune arthritis (34), is unknown. Our data suggests that microbial cues could impact not only the specificity but also the isotype of antibody responses generated locally.

Our data implicates the airway microbiota as a key player in the promotion of local IL-17A responses, and consequently the development of chronic lung disease. This pathway impacts upon both innate and adaptive inflammatory processes, regulates lymphoid neogenesis and the expansion of autoreactive $\mathrm{T}$ and $\mathrm{B}$ cells. The microbiota-enhanced local autoimmunity likely contributes to disease chronicity, although autoimmunity only represents one pathogenic mechanism linked with COPD. The characterization of dysbiotic microbial communities and 
their associated inflammatory signature could pave the way for personalized medicine to disrupt the chronic cycle of tissue damage and the heterogeneity seen in COPD.

\section{References:}

1. Rosenbaum L, Lamas D. Facing a "slow-motion disaster"--the un meeting on noncommunicable diseases. The New England journal of medicine 2011;365:2345-2348.

2. Halbert RJ, Natoli JL, Gano A, Badamgarav E, Buist AS, Mannino DM. Global burden of copd: Systematic review and meta-analysis. The European respiratory journal 2006;28:523532.

3. Fletcher C, Peto R. The natural history of chronic airflow obstruction. British medical journal 1977;1:1645-1648.

4. Saetta M, Finkelstein R, Cosio MG. Morphological and cellular basis for airflow limitation in smokers. The European respiratory journal 1994;7:1505-1515.

5. Tuder RM, Petrache I. Pathogenesis of chronic obstructive pulmonary disease. The Journal of clinical investigation 2012;122:2749-2755.

6. Finkelstein R, Fraser RS, Ghezzo H, Cosio MG. Alveolar inflammation and its relation to emphysema in smokers. American journal of respiratory and critical care medicine $1995 ; 152: 1666-1672$.

7. Barnes PJ. Mediators of chronic obstructive pulmonary disease. Pharmacological reviews 2004;56:515-548.

8. Willemse BW, ten Hacken NH, Rutgers B, Lesman-Leegte IG, Postma DS, Timens W. Effect of 1-year smoking cessation on airway inflammation in copd and asymptomatic smokers. The European respiratory journal 2005;26:835-845. 
9. Zakharkina T, Heinzel E, Koczulla RA, Greulich T, Rentz K, Pauling JK, Baumbach J, Herrmann M, Grunewald C, Dienemann H, von Muller L, Bals R. Analysis of the airway microbiota of healthy individuals and patients with chronic obstructive pulmonary disease by trflp and clone sequencing. PloS one 2013;8:e68302.

10. Sze MA, Dimitriu PA, Hayashi S, Elliott WM, McDonough JE, Gosselink JV, Cooper J, Sin DD, Mohn WW, Hogg JC. The lung tissue microbiome in chronic obstructive pulmonary disease. American journal of respiratory and critical care medicine 2012;185:1073-1080.

11. Han MK, Huang YJ, Lipuma JJ, Boushey HA, Boucher RC, Cookson WO, Curtis JL, Erb-Downward J, Lynch SV, Sethi S, Toews GB, Young VB, Wolfgang MC, Huffnagle GB, Martinez FJ. Significance of the microbiome in obstructive lung disease. Thorax 2012;67:456463.

12. Erb-Downward JR, Huffnagle GB, Martinez FJ. The microbiota in respiratory disease. American journal of respiratory and critical care medicine 2012;185:1037-1038.

13. Erb-Downward JR, Thompson DL, Han MK, Freeman CM, McCloskey L, Schmidt LA, Young VB, Toews GB, Curtis JL, Sundaram B, Martinez FJ, Huffnagle GB. Analysis of the lung microbiome in the "healthy" smoker and in copd. PloS one 2011;6:e16384.

14. Hilty M, Burke C, Pedro H, Cardenas P, Bush A, Bossley C, Davies J, Ervine A, Poulter L, Pachter L, Moffatt MF, Cookson WO. Disordered microbial communities in asthmatic airways. PloS one 2010;5:e8578.

15. Chambers DC, Gellatly SL, Hugenholtz P, Hansbro PM. Jtd special edition 'hot topics in copd'-the microbiome in copd. Journal of thoracic disease 2014;6:1525-1531.

16. Cui L, Morris A, Huang L, Beck JM, Twigg HL, 3rd, von Mutius E, Ghedin E. The microbiome and the lung. Annals of the American Thoracic Society 2014;11 Suppl 4:S227-232. 
17. Dickson RP, Martinez FJ, Huffnagle GB. The role of the microbiome in exacerbations of chronic lung diseases. Lancet 2014;384:691-702.

18. Rogers GB, Shaw D, Marsh RL, Carroll MP, Serisier DJ, Bruce KD. Respiratory microbiota: Addressing clinical questions, informing clinical practice. Thorax 2015;70:74-81.

19. Frank DN, St Amand AL, Feldman RA, Boedeker EC, Harpaz N, Pace NR. Molecularphylogenetic characterization of microbial community imbalances in human inflammatory bowel diseases. Proc Natl Acad Sci U S A 2007;104:13780-13785.

20. Manichanh C, Rigottier-Gois L, Bonnaud E, Gloux K, Pelletier E, Frangeul L, Nalin R, Jarrin C, Chardon P, Marteau P, Roca J, Dore J. Reduced diversity of faecal microbiota in crohn's disease revealed by a metagenomic approach. Gut 2006;55:205-211.

21. Agusti A, MacNee W, Donaldson K, Cosio M. Hypothesis: Does copd have an autoimmune component? Thorax 2003;58:832-834.

22. Brusselle GG, Demoor T, Bracke KR, Brandsma CA, Timens W. Lymphoid follicles in (very) severe copd: Beneficial or harmful? The European respiratory journal 2009;34:219-230.

23. Aloisi F, Pujol-Borrell R. Lymphoid neogenesis in chronic inflammatory diseases. Nature reviews Immunology 2006;6:205-217.

24. Hogg JC, Chu F, Utokaparch S, Woods R, Elliott WM, Buzatu L, Cherniack RM, Rogers RM, Sciurba FC, Coxson HO, Pare PD. The nature of small-airway obstruction in chronic obstructive pulmonary disease. The New England journal of medicine 2004;350:2645-2653.

25. van der Strate BW, Postma DS, Brandsma CA, Melgert BN, Luinge MA, Geerlings M, Hylkema MN, van den Berg A, Timens W, Kerstjens HA. Cigarette smoke-induced emphysema: A role for the $b$ cell? American journal of respiratory and critical care medicine 2006;173:751758. 
26. Bracke KR, Verhamme FM, Seys LJ, Bantsimba-Malanda C, Cunoosamy DM, Herbst R, Hammad H, Lambrecht BN, Joos GF, Brusselle GG. Role of cxcl13 in cigarette smoke-induced lymphoid follicle formation and chronic obstructive pulmonary disease. American journal of respiratory and critical care medicine 2013;188:343-355.

27. Mori M, Andersson CK, Svedberg KA, Glader P, Bergqvist A, Shikhagaie M, Lofdahl CG, Erjefalt JS. Appearance of remodelled and dendritic cell-rich alveolar-lymphoid interfaces provides a structural basis for increased alveolar antigen uptake in chronic obstructive pulmonary disease. Thorax 2013;68:521-531.

28. Bonarius HP, Brandsma CA, Kerstjens HA, Koerts JA, Kerkhof M, NizankowskaMogilnicka E, Roozendaal C, Postma DS, Timens W. Antinuclear autoantibodies are more prevalent in copd in association with low body mass index but not with smoking history. Thorax 2011;66:101-107.

29. Cottin V, Fabien N, Khouatra C, Moreira A, Cordier JF. Anti-elastin autoantibodies are not present in combined pulmonary fibrosis and emphysema. The European respiratory journal 2009;33:219-221.

30. Feghali-Bostwick CA, Gadgil AS, Otterbein LE, Pilewski JM, Stoner MW, Csizmadia E, Zhang Y, Sciurba FC, Duncan SR. Autoantibodies in patients with chronic obstructive pulmonary disease. American journal of respiratory and critical care medicine 2008;177:156163.

31. Lee SH, Goswami S, Grudo A, Song LZ, Bandi V, Goodnight-White S, Green L, Hacken-Bitar J, Huh J, Bakaeen F, Coxson HO, Cogswell S, Storness-Bliss C, Corry DB, Kheradmand F. Antielastin autoimmunity in tobacco smoking-induced emphysema. Nature medicine 2007;13:567-569. 
32. Rinaldi M, Lehouck A, Heulens N, Lavend'homme R, Carlier V, Saint-Remy JM, Decramer M, Gayan-Ramirez G, Janssens W. Antielastin b-cell and t-cell immunity in patients with chronic obstructive pulmonary disease. Thorax 2012;67:694-700.

33. Lochner M, Ohnmacht C, Presley L, Bruhns P, Si-Tahar M, Sawa S, Eberl G. Microbiota-induced tertiary lymphoid tissues aggravate inflammatory disease in the absence of rorgamma $t$ and lti cells. The Journal of experimental medicine 2011;208:125-134.

34. Wu HJ, Ivanov, II, Darce J, Hattori K, Shima T, Umesaki Y, Littman DR, Benoist C, Mathis D. Gut-residing segmented filamentous bacteria drive autoimmune arthritis via t helper 17 cells. Immunity 2010;32:815-827.

35. Berer K, Mues M, Koutrolos M, Rasbi ZA, Boziki M, Johner C, Wekerle H, Krishnamoorthy G. Commensal microbiota and myelin autoantigen cooperate to trigger autoimmune demyelination. Nature 2011;479:538-541.

36. Lee YK, Menezes JS, Umesaki Y, Mazmanian SK. Proinflammatory t-cell responses to gut microbiota promote experimental autoimmune encephalomyelitis. Proc Natl Acad Sci US A 2011;108 Suppl 1:4615-4622.

37. Sajjan U, Ganesan S, Comstock AT, Shim J, Wang Q, Nagarkar DR, Zhao Y, Goldsmith AM, Sonstein J, Linn MJ, Curtis JL, Hershenson MB. Elastase- and lps-exposed mice display altered responses to rhinovirus infection. American journal of physiology 2009;297:L931-944.

38. Caporaso JG, Kuczynski J, Stombaugh J, Bittinger K, Bushman FD, Costello EK, Fierer N, Pena AG, Goodrich JK, Gordon JI, Huttley GA, Kelley ST, Knights D, Koenig JE, Ley RE, Lozupone CA, McDonald D, Muegge BD, Pirrung M, Reeder J, Sevinsky JR, Turnbaugh PJ, Walters WA, Widmann J, Yatsunenko T, Zaneveld J, Knight R. Qiime allows analysis of highthroughput community sequencing data. Nature methods 2010;7:335-336. 
39. Edgar RC. Search and clustering orders of magnitude faster than blast. Bioinformatics 2010;26:2460-2461.

40. DeSantis TZ, Hugenholtz P, Larsen N, Rojas M, Brodie EL, Keller K, Huber T, Dalevi D, Hu P, Andersen GL. Greengenes, a chimera-checked 16s rrna gene database and workbench compatible with arb. Applied and environmental microbiology 2006;72:5069-5072.

41. team Rdc. R: A language and environment for statistical computing. $R$ Foundation for Statistical Computing, Vienna, Austria 2008;ISBN 3-900051-07-0.

42. Marsland BJ, Kurrer M, Reissmann R, Harris NL, Kopf M. Nippostrongylus brasiliensis infection leads to the development of emphysema associated with the induction of alternatively activated macrophages. European journal of immunology 2008;38:479-488.

43. Park H, Shin JW, Park SG, Kim W. Microbial communities in the upper respiratory tract of patients with asthma and chronic obstructive pulmonary disease. PloS one 2014;9:e109710.

44. Engler K, Muhlemann K, Garzoni C, Pfahler H, Geiser T, von Garnier C. Colonisation with pseudomonas aeruginosa and antibiotic resistance patterns in copd patients. Swiss medical weekly 2012;142:w13509.

45. Lambiase A, Del Pezzo M, Raia V, Sepe A, Ferri P, Rossano F. Chryseobacterium respiratory tract infections in patients with cystic fibrosis. The Journal of infection 2007;55:518523.

46. Zhang J, Chu S, Zhong X, Lao Q, He Z, Liang Y. Increased expression of cd4+il-17+ cells in the lung tissue of patients with stable chronic obstructive pulmonary disease (copd) and smokers. International immunopharmacology 2013;15:58-66. 
47. Podolin PL, Foley JP, Carpenter DC, Bolognese BJ, Logan GA, Long E, 3rd, Harrison OJ, Walsh PT. T cell depletion protects against alveolar destruction due to chronic cigarette smoke exposure in mice. American journal of physiology 2013;304:L312-323.

48. Kurimoto E, Miyahara N, Kanehiro A, Waseda K, Taniguchi A, Ikeda G, Koga H, Nishimori H, Tanimoto Y, Kataoka M, Iwakura Y, Gelfand EW, Tanimoto M. Il-17a is essential to the development of elastase-induced pulmonary inflammation and emphysema in mice. Respiratory research 2013;14:5.

49. Eppert BL, Wortham BW, Flury JL, Borchers MT. Functional characterization of $\mathrm{t}$ cell populations in a mouse model of chronic obstructive pulmonary disease. $J$ Immunol 2013;190:1331-1340.

50. Anthony D, Seow HJ, Uddin M, Thompson M, Dousha L, Vlahos R, Irving LB, Levy BD, Anderson GP, Bozinovski S. Serum amyloid a promotes lung neutrophilia by increasing il17a levels in the mucosa and gammadelta t cells. American journal of respiratory and critical care medicine 2013;188:179-186.

51. Chen K, Pociask DA, McAleer JP, Chan YR, Alcorn JF, Kreindler JL, Keyser MR, Shapiro SD, Houghton AM, Kolls JK, Zheng M. Il-17ra is required for ccl2 expression, macrophage recruitment, and emphysema in response to cigarette smoke. PloS one 2011;6:e20333.

52. Di Stefano A, Caramori G, Gnemmi I, Contoli M, Vicari C, Capelli A, Magno F, D'Anna SE, Zanini A, Brun P, Casolari P, Chung KF, Barnes PJ, Papi A, Adcock I, Balbi B. T helper type 17-related cytokine expression is increased in the bronchial mucosa of stable chronic obstructive pulmonary disease patients. Clinical and experimental immunology 2009;157:316324. 
53. Taraseviciene-Stewart L, Douglas IS, Nana-Sinkam PS, Lee JD, Tuder RM, Nicolls MR, Voelkel NF. Is alveolar destruction and emphysema in chronic obstructive pulmonary disease an immune disease? Proceedings of the American Thoracic Society 2006;3:687-690.

54. Sullivan AK, Simonian PL, Falta MT, Mitchell JD, Cosgrove GP, Brown KK, Kotzin BL, Voelkel NF, Fontenot AP. Oligoclonal cd4 $+\mathrm{t}$ cells in the lungs of patients with severe emphysema. American journal of respiratory and critical care medicine 2005;172:590-596.

55. Marsland BJ, Yadava K, Nicod LP. The airway microbiome and disease. Chest 2013;144:632-637.

56. Naik S, Bouladoux N, Wilhelm C, Molloy MJ, Salcedo R, Kastenmuller W, Deming C, Quinones M, Koo L, Conlan S, Spencer S, Hall JA, Dzutsev A, Kong H, Campbell DJ, Trinchieri G, Segre JA, Belkaid Y. Compartmentalized control of skin immunity by resident commensals. Science 2012;337:1115-1119.

57. Molyneaux PL, Mallia P, Cox MJ, Footitt J, Willis-Owen SA, Homola D, TrujilloTorralbo MB, Elkin S, Kon OM, Cookson WO, Moffatt MF, Johnston SL. Outgrowth of the bacterial airway microbiome after rhinovirus exacerbation of chronic obstructive pulmonary disease. American journal of respiratory and critical care medicine 2013;188:1224-1231.

58. Venkataraman A, Bassis CM, Beck JM, Young VB, Curtis JL, Huffnagle GB, Schmidt TM. Application of a neutral community model to assess structuring of the human lung microbiome. mBio 2015;6.

59. Bassis CM, Erb-Downward JR, Dickson RP, Freeman CM, Schmidt TM, Young VB, Beck JM, Curtis JL, Huffnagle GB. Analysis of the upper respiratory tract microbiotas as the source of the lung and gastric microbiotas in healthy individuals. mBio 2015;6:e00037. 
60. Shaw MH, Kamada N, Kim YG, Nunez G. Microbiota-induced il-1beta, but not il-6, is critical for the development of steady-state th17 cells in the intestine. The Journal of experimental medicine 2012;209:251-258.

61. Martin B, Hirota K, Cua DJ, Stockinger B, Veldhoen M. Interleukin-17-producing gammadelta $\mathrm{t}$ cells selectively expand in response to pathogen products and environmental signals. Immunity 2009;31:321-330.

62. Duan J, Chung H, Troy E, Kasper DL. Microbial colonization drives expansion of il-1 receptor 1-expressing and il-17-producing gamma/delta t cells. Cell host \& microbe 2010;7:140150.

63. Trompette A, Gollwitzer ES, Yadava K, Sichelstiel AK, Sprenger N, Ngom-Bru C, Blanchard C, Junt T, Nicod LP, Harris NL, Marsland BJ. Gut microbiota metabolism of dietary fiber influences allergic airway disease and hematopoiesis. Nature medicine 2014;20:159-166.

64. Yadava K, Marsland BJ. Lymphoid follicles in chronic lung diseases. Thorax 2013;68:597-598.

65. Kirkham PA, Caramori G, Casolari P, Papi AA, Edwards M, Shamji B, Triantaphyllopoulos K, Hussain F, Pinart M, Khan Y, Heinemann L, Stevens L, Yeadon M, Barnes PJ, Chung KF, Adcock IM. Oxidative stress-induced antibodies to carbonyl-modified protein correlate with severity of chronic obstructive pulmonary disease. American journal of respiratory and critical care medicine 2011;184:796-802.

66. Seys LJ, Verhamme FM, Schinwald A, Hammad H, Cunoosamy DM, BantsimbaMalanda C, Sabirsh A, McCall E, Flavell L, Herbst R, Provoost S, Lambrecht BN, Joos GF, Brusselle GG, Bracke KR. Role of b cell-activating factor in chronic obstructive pulmonary disease. American journal of respiratory and critical care medicine 2015;192:706-718. 
67. Curtis JL, Freeman CM, Huffnagle GB. "B" for bad, beneficial, or both? Lung lymphoid neogenesis in chronic obstructive pulmonary disease. American journal of respiratory and critical care medicine 2015;192:648-651.

68. Brandsma CA, Kerstjens HA, van Geffen WH, Geerlings M, Postma DS, Hylkema MN, Timens W. Differential switching to igg and iga in active smoking copd patients and healthy controls. The European respiratory journal 2012;40:313-321.

69. Murphy TF, Brauer AL, Grant BJ, Sethi S. Moraxella catarrhalis in chronic obstructive pulmonary disease: Burden of disease and immune response. American journal of respiratory and critical care medicine 2005;172:195-199. 


\section{Figure legends}

\section{Figure 1: Murine model of chronic pulmonary inflammation mimics key pathological} features of human disease. (A) BALB/c mice were administered LPS (7ug) and elastase (1.5U) in a volume of 100ul intranasally once a week for 4 weeks. Terminal analysis was carried out 1 week after the last challenge. (B) Lung compliance and (C) FEV0.1/FVC were measured by FlexiVent invasive airway mechanics system. (D) Paraformaldehyde fixed sections of lung were stained with hematoxylin and eosin (Hand E) and emphysema and destruction of lungs was scored by (E) mean linear intercept and (F) destruction index (n=3-5). (G) Representative H and E stained lung sections showing perivascular and peribronchiolar inflammation in LPS/elastase treated mice. (H) The total cell and (I) differential counts in the broncho-alveolar alveolar lavage (BAL) was determined $(\mathrm{n}=5)$. Error bars represent standard error of mean. Data representative of at least 2 independent experiments. $* \mathrm{p} \leq 0.05, * * \mathrm{p} \leq 0.01, * * * \mathrm{p} \leq 0.001, * * * * \mathrm{p} \leq 0.0001$

\section{Figure 2: Chronic pulmonary inflammation is associated with lymphoid neogenesis,} enhanced local antibody responses and IL-17A production. (A) Representative pictures of brochial associated (BALT), vessel associated(VALT) and alveolar associated (ALT) lymphoid tissue in $\mathrm{H}$ and $\mathrm{E}$ stained lung sections and their quantification. Data pooled from 2 experiments $(n=6-8)$. (B) Germinal center B cells and (C) follicular T helper cells in cells from lungs were quantified by flow cytometry. Data pooled from 2 experiments. (D) Levels of IgG1, IgA and IgM in BAL supernatant were measured by ELISA. Data pooled from 2 experiments $(\mathrm{n}=8-9)$. Collagen and elastin specific (E) IgG1 (F) $\operatorname{IgA}$ and (G) $\operatorname{IgM}$ responses were quantified by ELISA. Data pooled from 2 experiments $(n=8-9)$. (H) Cells isolated from lungs and airways of indicated groups were stimulated in vitro with PMA, ionomycin and monensin for 4 hours. IL-17 
production by $\gamma \delta \square$ T cells was quantified by flow cytometry. Data representative of at least 3 independent experiments. (I) IL-17 production by CD4+ T cells was quantified by flow cytometry in cells isolated from lungs and airways of indicated groups stimulated in vitro with PMA, ionomycin and monensin for 4 hours,. Data representative of at least 3 independent experiments. (J) FACS sorted $\gamma \delta \square$ T cells from pooled lungs and airways samples of 5 mice treated with LPS/elastase were stimulated with bone marrow derived dendritic cells (BMDCS) alone (media), or BMDCs pulsed with collagen or elastin. (K) CD4+ T cells were sorted by flow cytometry from pooled lungs and airways samples of 5 mice treated with LPS/elastase. Sorted CD4+ $\mathrm{T}$ cells were then stimulated with bone marrow derived dendritic cells (BMDCs) alone (media), or BMDCs pulsed with collagen or elastin. . *p $\leq 0.05, * * p \leq 0.01, * * * p \leq 0.001, * * * * p$ $\leq 0.0001$.

Figure 3: The pulmonary microbiota is altered upon the induction of chronic pulmonary inflammation. Eight mice per group were treated with PBS or LPS/Elastase for 4 weeks and DNA was extracted from 4 pooled BAL per group, resulting in 2 sample sets per group for Illumina MiSeq 16S rDNA sequencing. (A) Richness (chao1) and diversity (Shannon) rarefaction curves of the $16 \mathrm{~S}$ rDNA library constructed from pooled BAL of PBS or LPS/Elastase treated mice. (B) Heatmap showing the relative abundance of major bacterial genera (OTUs $>0.05 \%$ of relative abundance in minimum 2 samples) in pooled BAL of PBS or LPS/Elastase treated mice and negative control. Dendrogram was drawn from Ward hierarchical clustering algorithm using Bray-Curtis dissimilarity matrix. (C) Bar graphs representing the relative abundance of specific genera showing differences between the BAL of PBS or LPS/Elastase treated mice. OTU (Operational Taxonomic Unit). 
Figure 4: Microbiota derived signals amplify innate and adaptive inflammation in disease. Mice harboring a specific pathogen free (SPF) microflora (water) or mice depleted of microbiota by antibiotic treatment were subjected to LPS/elastase treatment over 4 weeks. Analysis was carried out a week after last challenge (A) Lung compliance and (B) FEV/FVC was measured using FlexiVent invasive airway mechanics system. Data are pooled from 2 experiments (C) Representative slides of $\mathrm{H}$ and $\mathrm{E}$ stained lung sections showing peri-broncheolar and perivascular inflammation in water and antibiotic treated groups (D) Number of cells infiltrating the broncho-alveolar lavage was determined. (E) Neutrophils, (F) alveolar and interstitial macrophages in the BAL were enumerated by flow cytometry. Data representative of 2 independent experiments. (G) Vascular associated, alveolar associated or bronchial associated lymphoid follicles were quantified in $\mathrm{H}$ and $\mathrm{E}$ sections of lungs. Error bars represent standard error of mean. $(n=4)(\mathbf{H})$ Levels of IgG1, IgA and IgM in BAL supernatant were measured by ELISA. Collagen and elastin specific (I) IgG1 (J) IgA responses were quantified by ELISA. Error bars represent standard error of mean. Data pooled from 2 experiments $(n=9) .{ }^{*} p \leq 0.05$, $* * \mathrm{p} \leq 0.01$

Figure 5: Microbiota enhances production of IL-17A by CD4+ and $\gamma \delta \square$ T cells. Cells isolated from lungs and airways of control (water) or antibiotic were stimulated in vitro with PMA, ionomycin and monensin for 4 hours. (A) Ex vivo stimulated cells were surface stained, fixed and permeabilized for detection of cytokines Interferon gamma and IL-17A. (B) Cellular sources of IL-17A were analyzed by flow cytometry. Pie charts represent the composition based on mean values from 4-5 mice per group. (C) Total number of CD4+ T cells producing IL-17A or (D) $\gamma \delta \square$ T cells were determined by flow cytometry. Data representative of 2 independent 
experiments. (E) Antibiotic treated mice were challenged with LPS/elastase on day 0,7 and 21. Everyday starting at day 12 until day 20 and then on days 22 to 24 , they received microbiota (sequenced in Figure 3) isolated from either PBS challenged SPF mice or LPS/elastase challenged SPF mice in 100ul intranasally. On day 25, cells isolated from the lungs of the recolonized antibiotic treated recipients were restimulated with PMA ionomycin and IL-17 production was analyzed by flow cytometry. Total number of IL-17A producing (F) CD4+ T cells and (G) $\gamma \delta \square \mathrm{T}$ cells were also determined by flow cytometry. ${ }^{*} \mathrm{p} \leq 0.05,{ }^{* *} \mathrm{p} \leq 0.01$.

\section{Figure 6: IL-17A kinetics correlates with disease severity and targeted neutralization of IL-} 17A ameliorates disease. (A) BALB/c mice were challenged with $1,2,3$ or 4 doses of LPS/elastase. Analysis was carried out 1 week after indicated number of challenges. (B) Invasive lung function measurement was carried out using the flexivent system. (C) The kinetics of ROR $\square \mathrm{t}$ expressing and IL-17A producing cells in ex vivo stimulated cells from lungs and airways of mice challenged with $1,2,3$ or 4 times PBS or LPS/elastase. ( $n=4-5$ per time point per group. The kinetics of IL-17A producing (D) CD4+ and (E) $\gamma \delta \square$ T cells in mice challenged with 1,2,3 or 4 times PBS or LPS/elastase. ( $n=4-5$ per time point per group). (F) Targeted neutralization of IL-17A based on its production in mild to severe disease. Mice were challenged with LPS/elastase over 4 weeks and administered anti IL-17A antibody or isotype control at indicated time points. (G) Lung compliance and (H) FEV/FVC was measured using the FlexiVent invasive airway mechanics system. (I) Number of cells recovered in the bronchoalveolar lavage was determined. (J) Neutrophils in the BAL were enumerated by differential cell counts. Data representative of atleast 2 independent experiments. (K) Vascular associated, alveolar associated or bronchial associated lymphoid follicles were quantified in $\mathrm{H}$ and $\mathrm{E}$ 
sections of lungs. Error bars represent standard error of mean. (n=4-5) (L) Levels of IgG1, IgA and IgM in BAL supernatant were measured by ELISA. Data pooled from 2 experiments $(\mathrm{n}=9)$. ${ }^{*} \mathrm{p} \leq 0.05, * * \mathrm{p} \leq 0.01,{ }^{* * *} \mathrm{p} \leq 0.001$. 
A

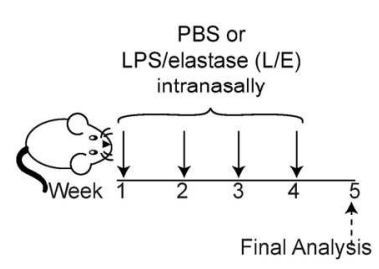

D

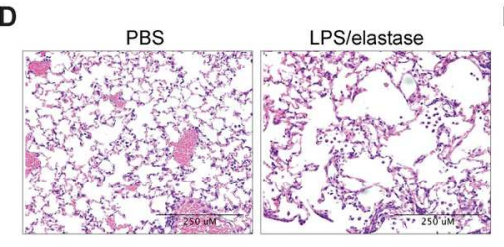

G

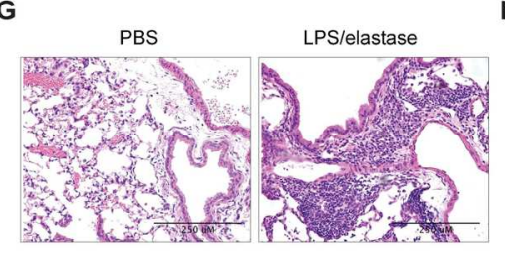

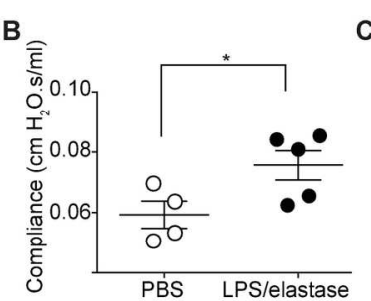
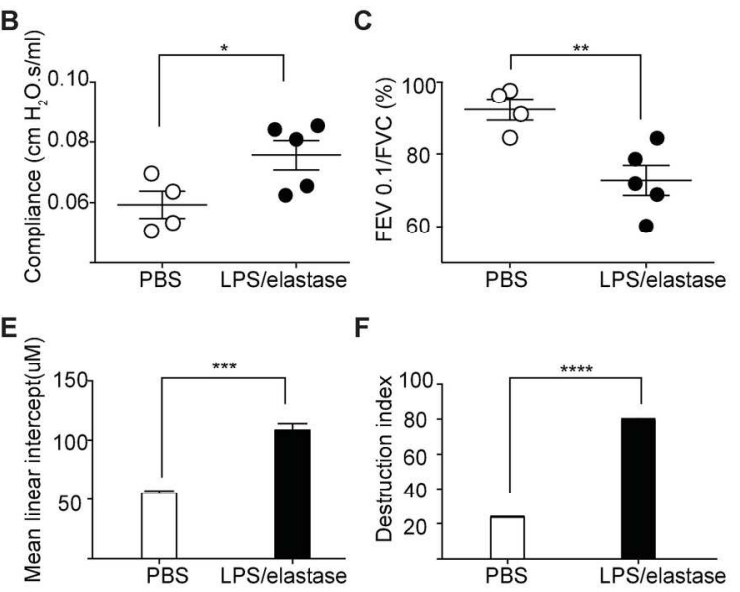

$\mathbf{F}$
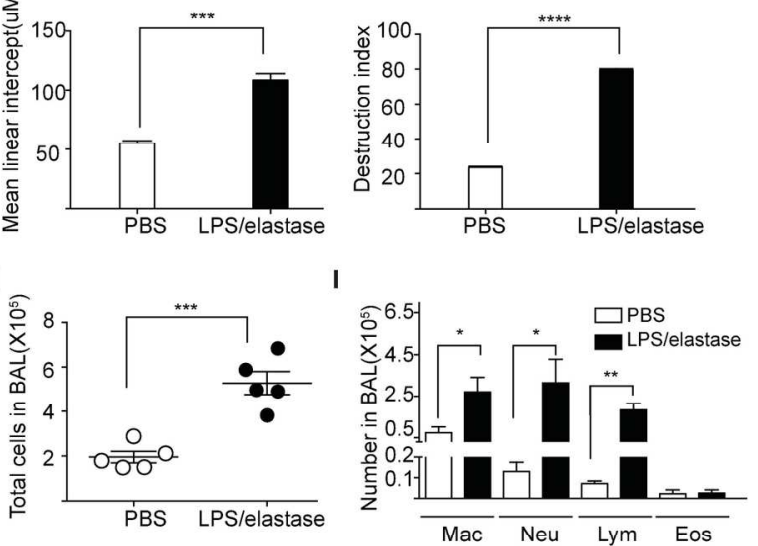

Figure 1

$170 \times 170 \mathrm{~mm}(300 \times 300$ DPI $)$ 

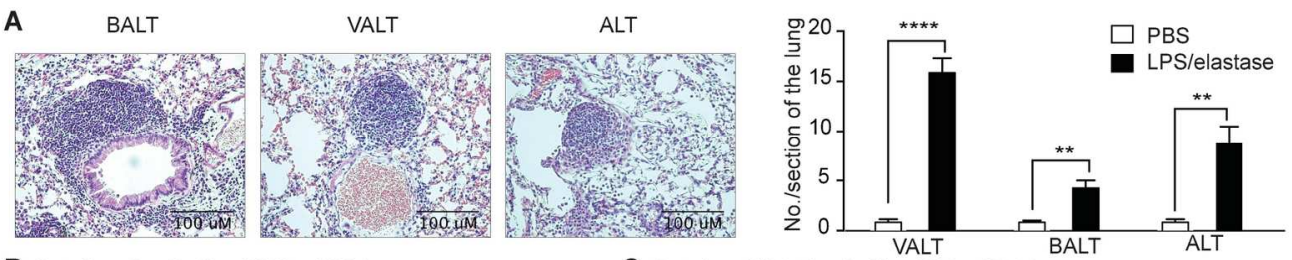

B Gated on B cells (IIve, B220+, CD3-)

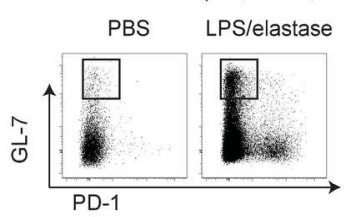

D
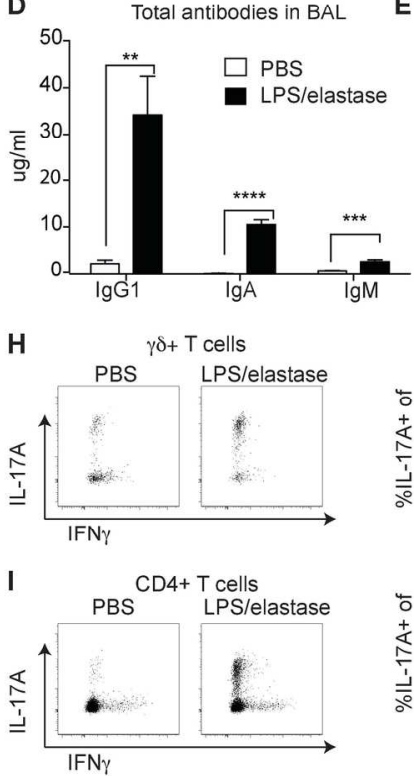

GC B cells

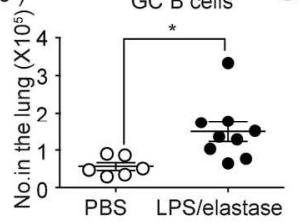

E

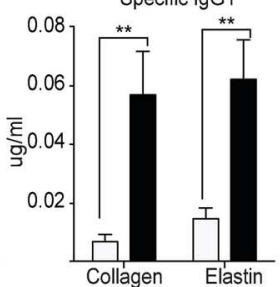

Gated on CD4+T cells (IIve, CD3+,CD4+)

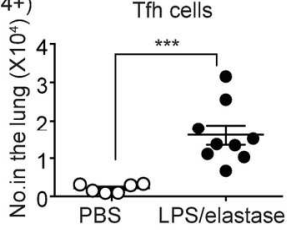

G PBS LPS/elastase

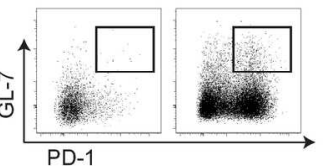

F
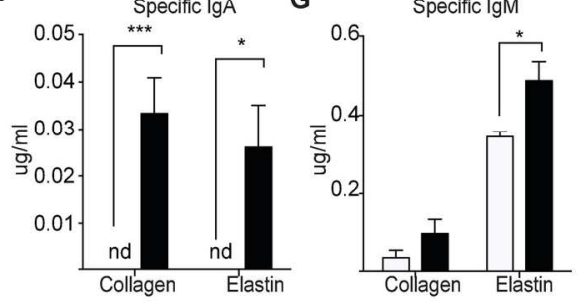

J
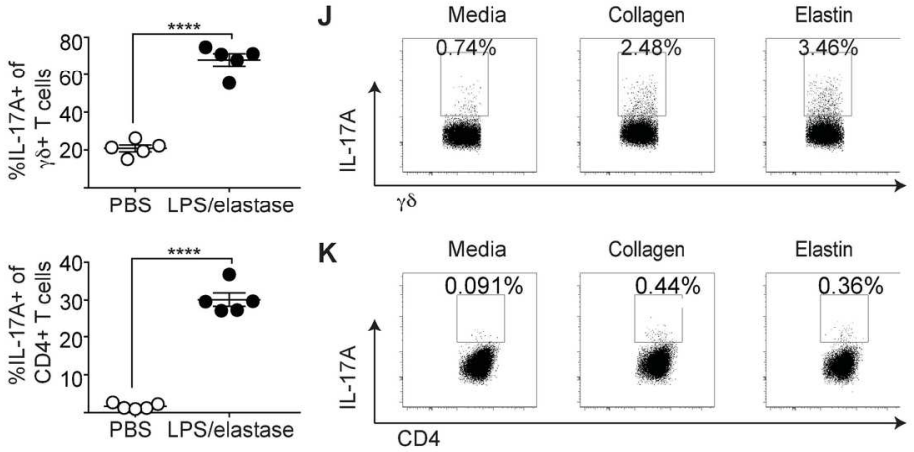

Figure 2

$170 \times 170 \mathrm{~mm}(300 \times 300$ DPI $)$ 

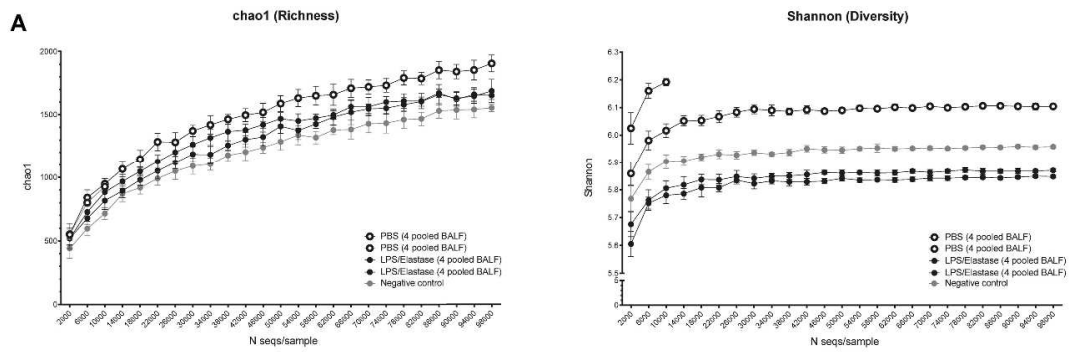

B

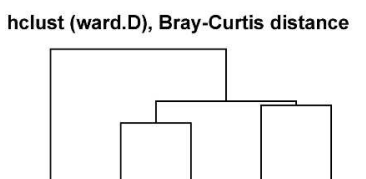

Relative abundance \%
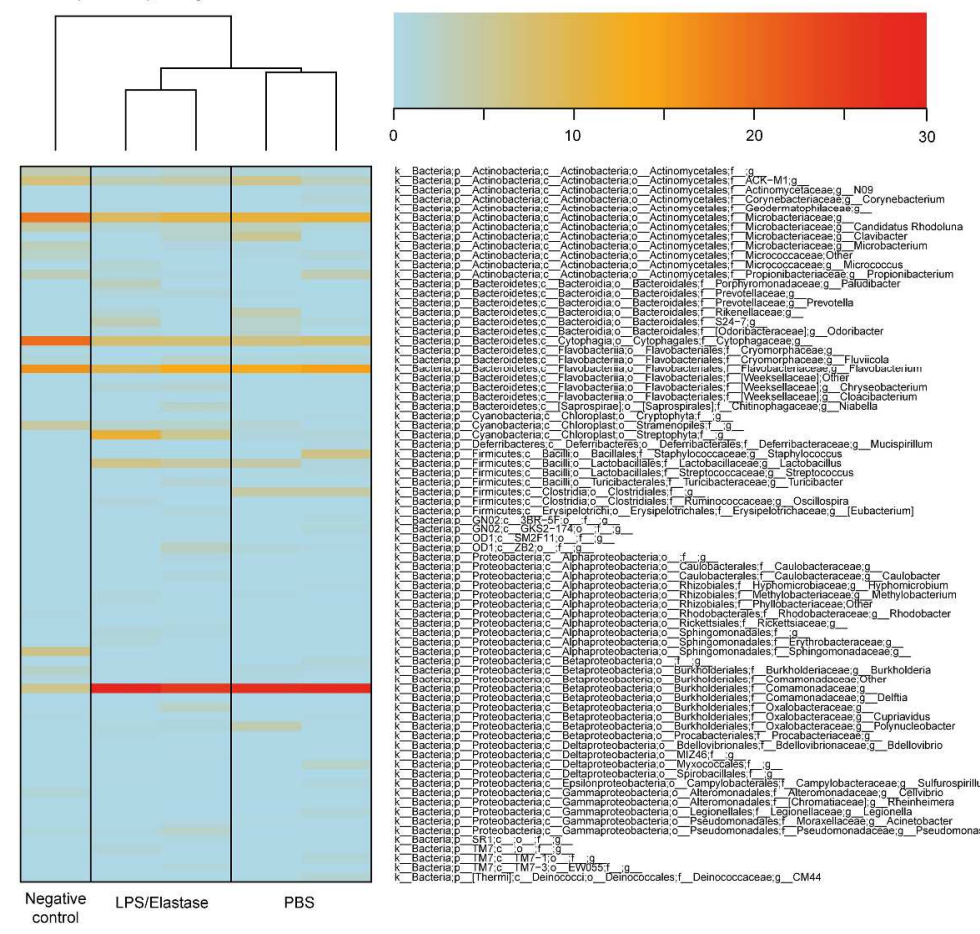

g_Prevotella
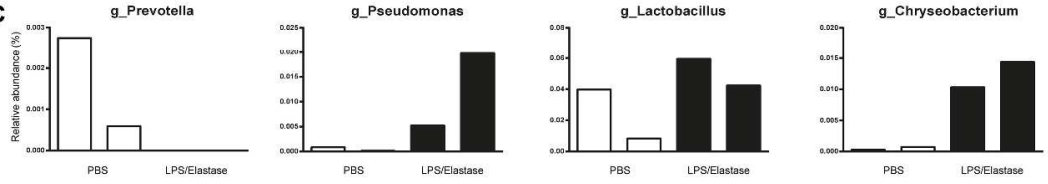

Figure 3

$297 \times 420 \mathrm{~mm}(300 \times 300$ DPI) 
A

B C
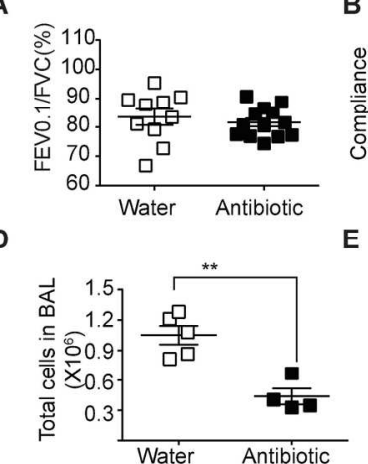

Water Antibiotic
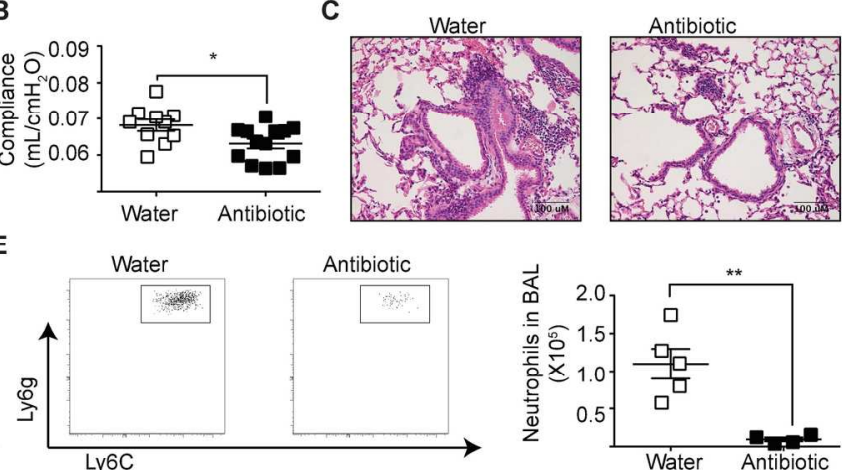

$\mathbf{F}$

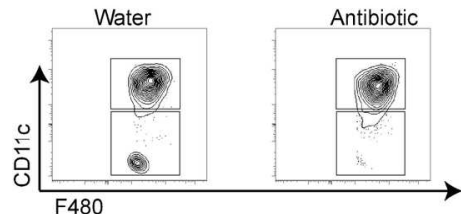

G

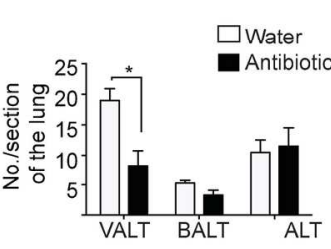

$\mathbf{H}$
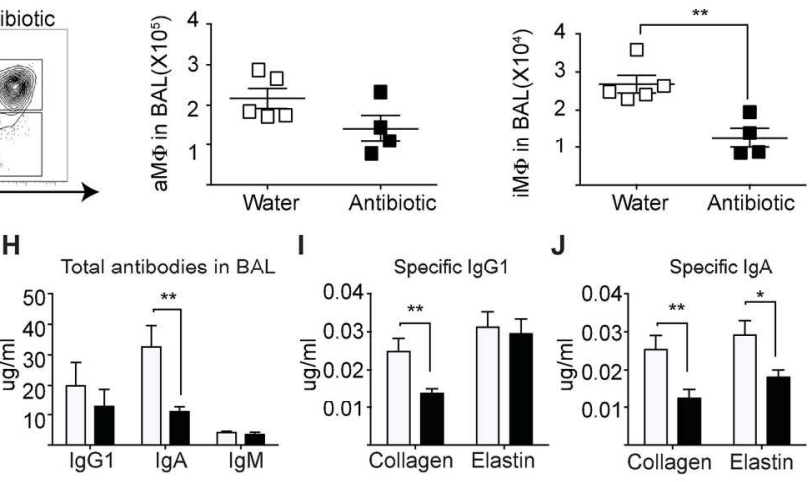

Figure 4

$170 \times 170 \mathrm{~mm}(300 \times 300$ DPI $)$ 

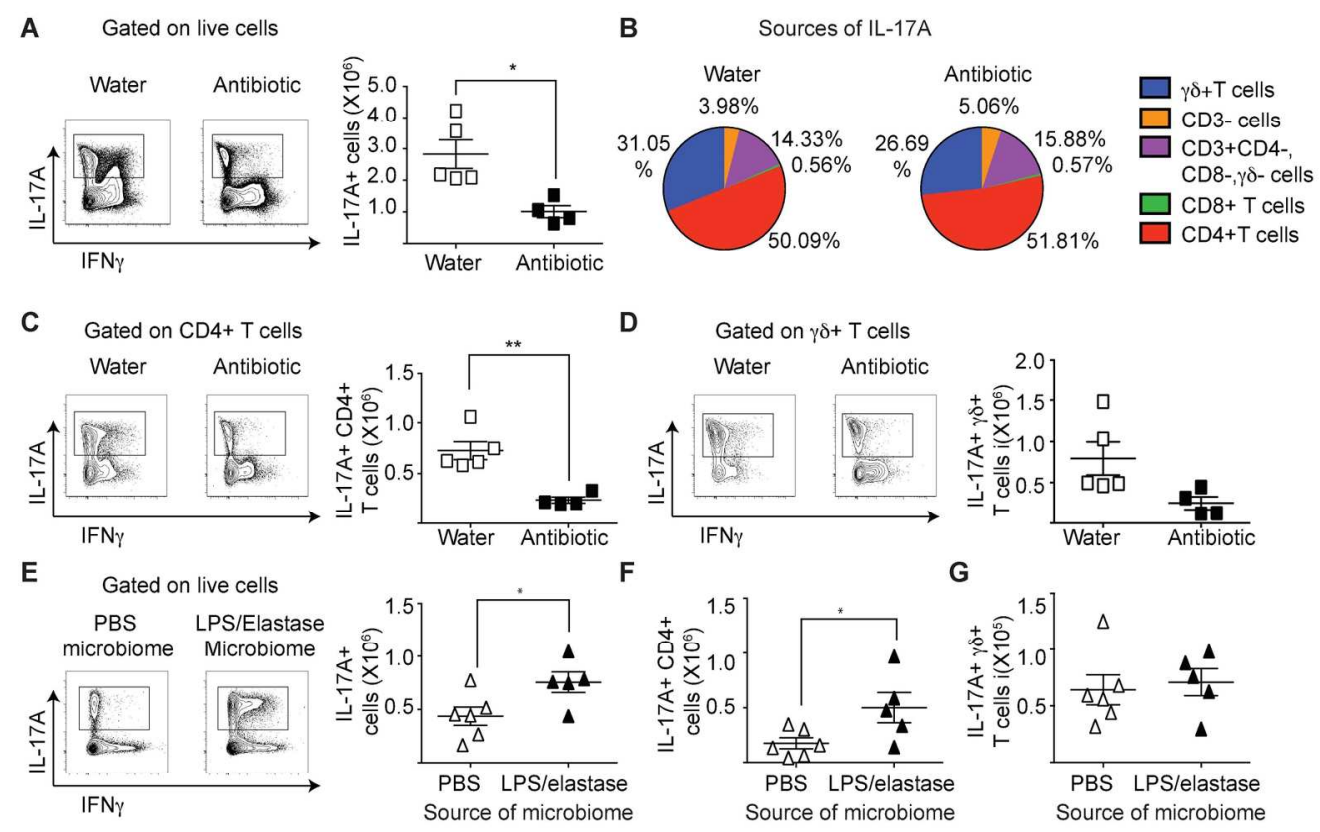

Figure 5

$170 \times 170 \mathrm{~mm}(300 \times 300 \mathrm{DPI})$ 

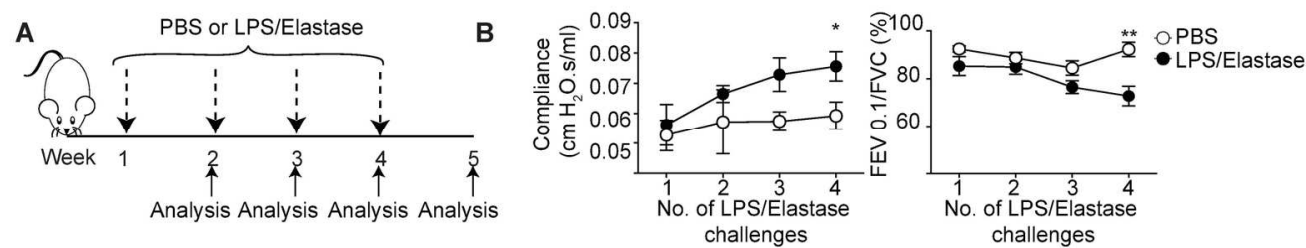

C

No. of LPS/Elastase challenges
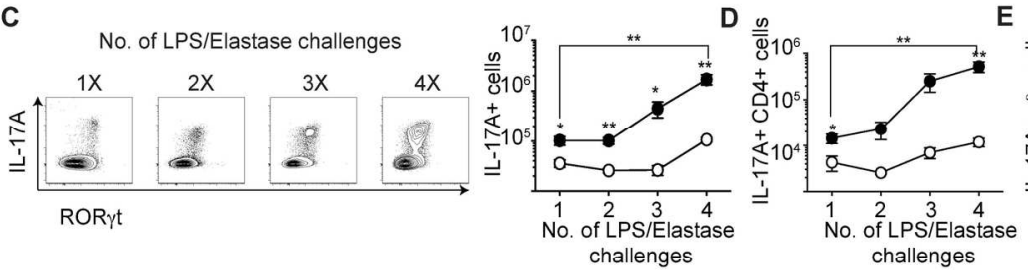

E
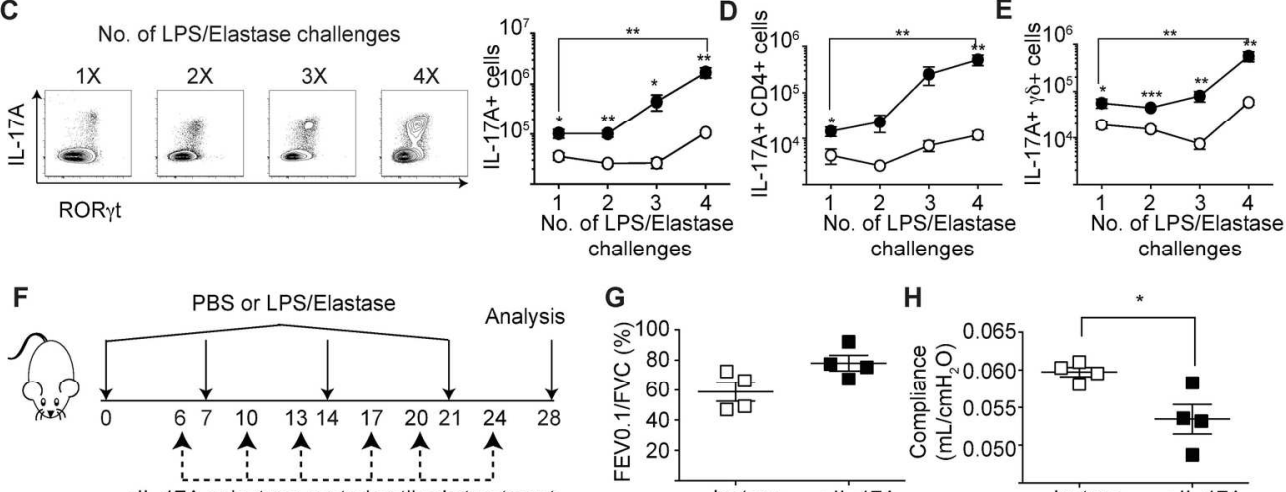

$\alpha \mathrm{LL}-17 \mathrm{~A}$ or isotype control antibody treatment

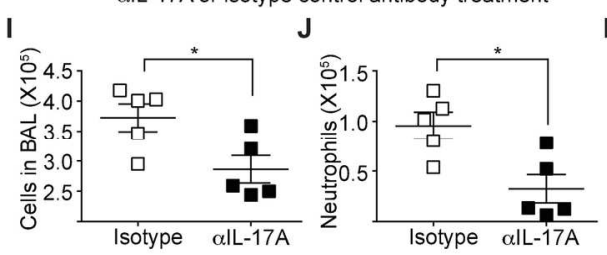

G

H
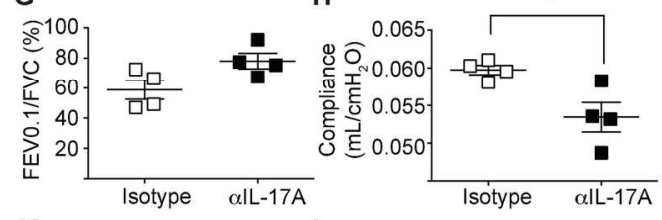

K

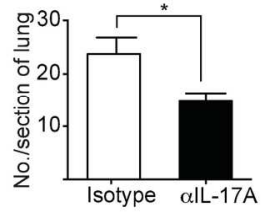

L

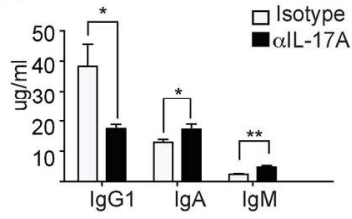

Figure 6

$170 \times 170 \mathrm{~mm}(300 \times 300$ DPI $)$ 


\section{Microbiota promotes chronic pulmonary inflammation by enhancing IL-17A and autoantibodies}

Koshika Yadava, Céline Pattaroni, Anke K. Sichelstiel, Aurélien Trompette, Eva S. Gollwitzer, Olawale Salami, Christophe von Garnier, Laurent P. Nicod, Benjamin J. Marsland

\section{Online data supplement}

\section{Supplementary methods}

Cell isolation from the lung and airways: Broncho alveolar lavage was performed in a volume of 1ml. Cells were counted using a coulter counter (IG Instrumenten- Gesellschaft AG, Basel, Switzerland). Isolated cells were subjected to differential cell staining using Diff-Quik solution (Dade Behring, Siemens Healthcare Diagnostics, Deerfield, IL) and also analyzed by flow cytometry. Single cell suspensions from lung and trachea were obtained by digestion with 2 $\mathrm{mg} / \mathrm{ml}$ Collagenase IV (Invitrogen) counted using a coulter counter and analyzed by flow cytometry.

Histological analysis: Lungs were inflated and fixed with 2\% PFA. Paraffin embedded sections of the lungs were subjected to hematoxylin and eosin (H\&E) using standard protocols. Pulmonary emphysema was quantified by measuring mean linear intercept for airspace enlargement and destruction index for alveolar wall destruction(1,2). Lymphoid follicles were defined as an association of over 50 cells and further discriminated on the basis of their location. Flow cytometry: A combination of the following antibodies was used for surface staining of cells CD11c APC-Cy7, CD11b PerCP-Cy5.5,F480 APC, Ly-6G Biotin, Ly-6C Pacific Blue, MHCII alexafluor 700, CD4 PerCP-Cy5.5, CD8b FITC, $\gamma \delta$ TCR Biotin, CD3 Pacific Blue, Streptavidin 
PE-Cy7. To analyze cytokine production, cells from lung digests were stimulated with $10^{-7} \mathrm{M}$ PMA, $1 \mathrm{ug} / \mathrm{ml}$ ionomycin and $2 \times 10^{-6} \mathrm{M}$ monensin for $4 \mathrm{~h}$ at $37^{\circ} \mathrm{C}$ (indicated chemicals were purchased from Sigma-Aldrich). Subsequently, cells were surface stained, fixed and stained intracellularly with ROR $\square$ tPE, IFN $\square$ APC, IL-17A Alexa700. All antibodies were purchased from Biolegend. Stained cells were acquired on a BD FACS CANTO or BD FACS LSRII and analyzed by using FlowJo software (Tree Star). For specific restimulation bone marrow derived dendritic cells were cultured with mouse lung collagen at $2 \mathrm{ug} / \mathrm{ml}$ (elastin products company) or elastin peptides at $2 \mathrm{ug} / \mathrm{ml}$ or media overnight. FACS sorted CD4 and $\square \square \mathrm{T}$ cells were cultured with these BMDCs and monensin for 4 hours at 37 degrees. Subsequently, cells were surface stained, fixed and stained intracellularly.

ELISA: Total immunoglobulin (Ig) in serum and BAL were determined by ELISA. Briefly, NUNC MaxiSorp 96-well plates were coated with either 2ug/ml goat anti-mouse IgG1, IgA, IgM. Samples were incubated overnight at $4{ }^{\circ} \mathrm{C}$ prior to addition of $1 \mathrm{ug} / \mathrm{ml}$ final of alkalinephosphatase-conjugated goat anti-mouse IgG1, IgA or IgM (all antibodies were from SouthernBiotech, Birmingham, AL). For detection of specific responses the plates were coated with mouse collagen at $50 \mathrm{ug} / \mathrm{ml}$ (elastin products company), elastin peptides at $10 \mathrm{ug} / \mathrm{ml}($ elastin products company). 


\section{Supplementary figures:}

Figure E1: Changes induced by LPS/elastase treatment are chronic. (A) BALB/c mice were administered LPS (7ug) and elastase (1.5U) in a volume of 100ul intranasally once a week for 4 weeks. Terminal analysis was carried out 8 weeks after the last challenge. (B) Paraformaldehydes fixed sections of lung were stained with hematoxylin and eosin (Hand E) and emphysema was scored by mean liner intercept. Error bars represent standard error of mean.(n=3-5) (C) The total cell and (D) differential counts in the bronchiolar alveolar lavage (BAL) was determined. (D) Representative slides showing persistence of hemosiderin-laden macrophages in BAL of mice administered LPS/elastase. Arrows show the HLM. (E) Lymphoid follicles were further quantified based on there location as either vascular associated, alveolar associated or bronchial associated. Error bars represent standard error of mean. $(n=3-5)$

\section{Figure E2: Systemic antibody levels are largely unaffected in chronic pulmonary} inflammation. (A)Levels of $\operatorname{IgG1}$, and $\operatorname{IgA}$ in serum of mice treated with PBS or LPS/elastase were measured by ELISA. Error bars represent standard error of mean. Data pooled from 2 experiments. $(\mathrm{n}=10)$ (B) Collagen and elastin specific IgG1 and (C) $\operatorname{IgA}$ responses were quantified by ELISA. Error bars represent standard error of mean Data pooled from 2 experiments $(\mathrm{n}=10)$.

Figure E3: LPS/elastase treatment results in increase in the levels of cytokines associated with the IL-17A pathway. Levels of (A) IL-6, (B) IL-1 $\beta$ and (C) IL-17A were measured in 
BAL supernatant of indicated groups $(n=4)$ by multiplex assay. Data representative of at least 2 independent experiments.

Figure E4: Antibiotic treatment efficiently reduces the total microbial load. DNA was extracted from the feces of PBS or LPS/elastase treated mice. qPCR amplified $292 \mathrm{bp}$ fragment of v1-v2 rRNA gene for detection of all bacteria. Number of copies determined using a standard curve.

Figure E5: Gating strategy to identify (A) alveolar macrophages and interstitial macrophages and (B) IL-17 producing cells

Figure E6: Microbiota enhances IL-17A in chronic pulmonary inflammation. SPF and germ free mice were treated with LPS/elastase for 4 weeks. (A) Total cells infiltrating the BAL were determined. (B) Neutrophils and (C, D) macrophage subsets in the BAL were enumerated by flow cytometry. (E)Total number of $\gamma \delta+\mathrm{T}$ cells as well as IL-17 producing $\gamma \delta+\mathrm{T}$ cells in the lungs and airways were quantified by flow cytometry. (F) Germ free mice were challenged with LPS/elastase on day 0,7 and 21. Everyday starting at day 12 until day 20 and then on days 22 to 24, they received microbiome isolated from either PBS challenged SPF mice or LPS/elatase challenged SPF mice in 100ul intranasally. Terminal analysis was carried out on day 25. Cells isolated from the lungs of the recolonized germ free recipients were restimulated with PMA ionomycin and IL-17 production in CD $4+$ and $\gamma \delta+$ T cells was analyzed by flow cytometry.

Figure E7: Temporal changes in cellular sources of IL-17 in disease. The kinetics of IL-17A production by ex vivo stimulated cells from mice challenged with 1,2,3 or 4 times PBS or 
LPS/Elastase. ( $n=4-5$ per time point per group) pie charts showing the cellular sources of IL-17A in 1 time or 4 times PBS treated mice versus 1 time LPS/elastase or 4 times LPS /Elastase treated mice. Pie charts represent mean of 4-5 mice per group. 
A

B
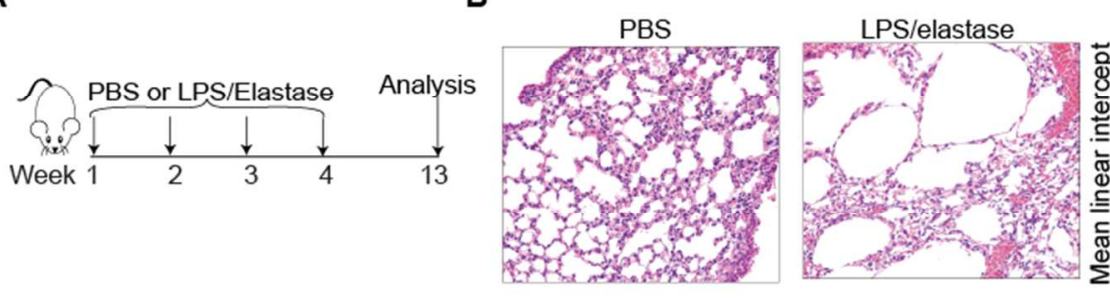

c

D
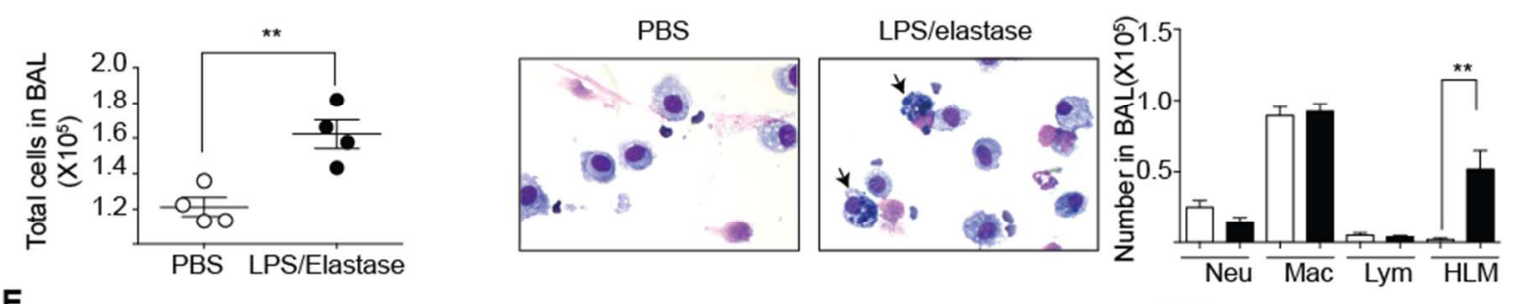

E

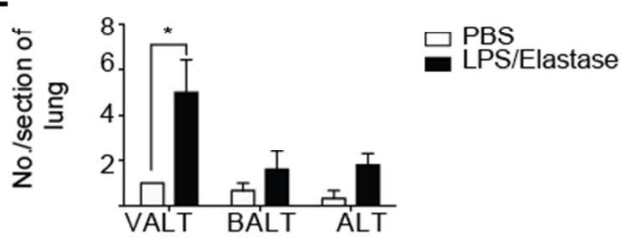

므 $\mathrm{PBS}^{\mathrm{LPS} / \text { Elastase }}$

\section{Figure E1}



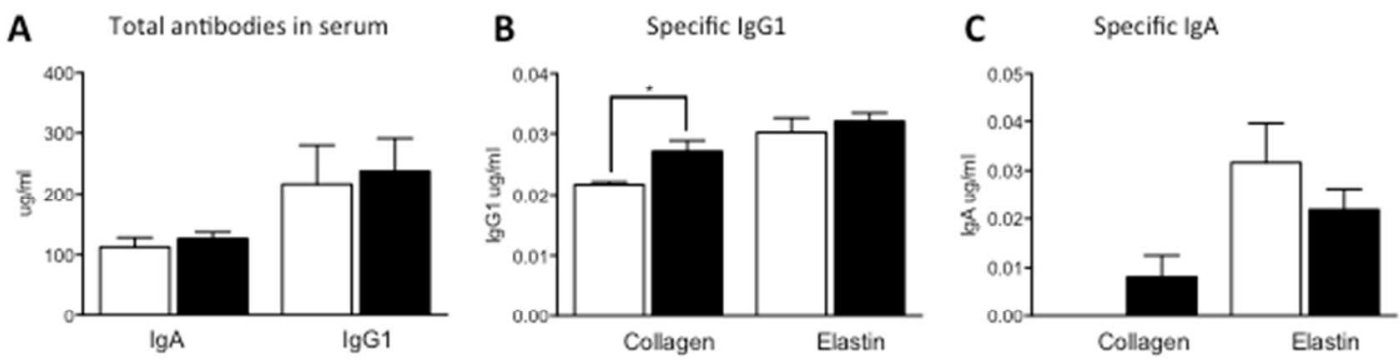

\section{$\square$ PBS \\ - LPS/Elastase}

\section{Figure E2}


A IL-6

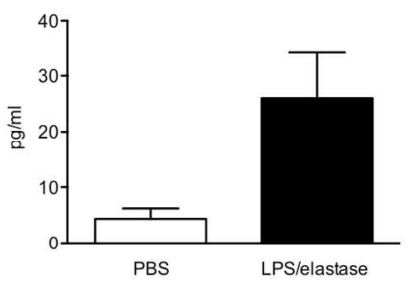

B

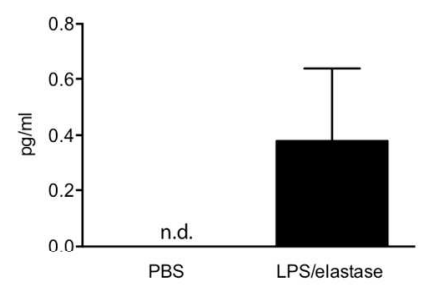

C

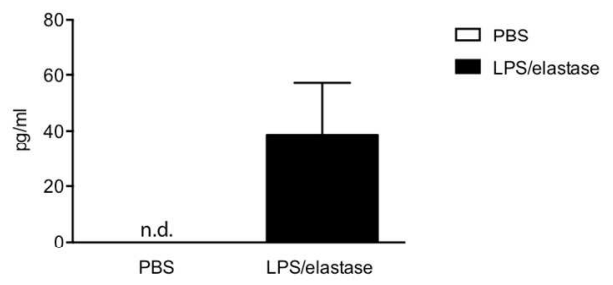

Figure E3 


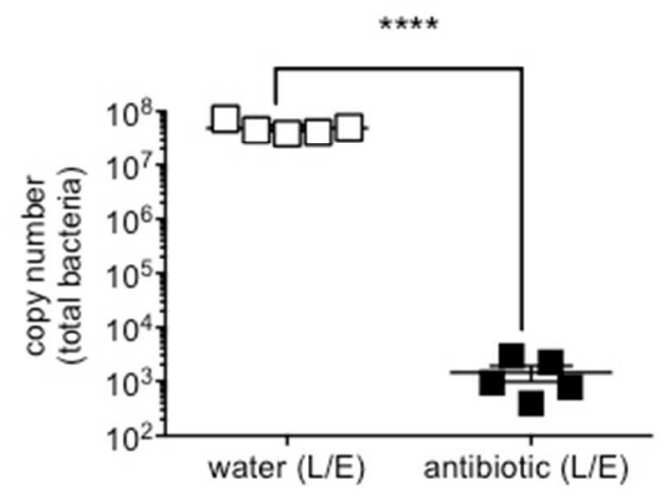

Figure E4 
A

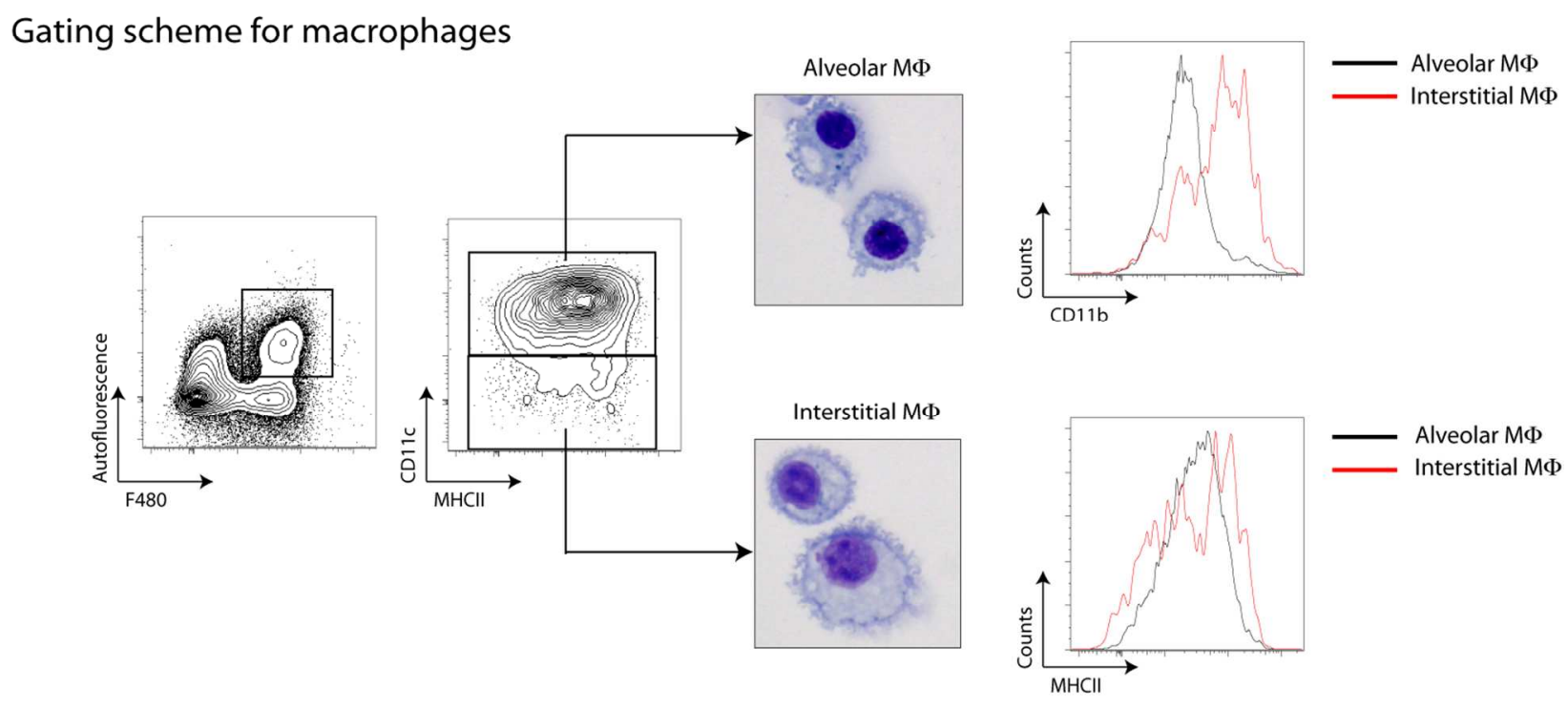

B

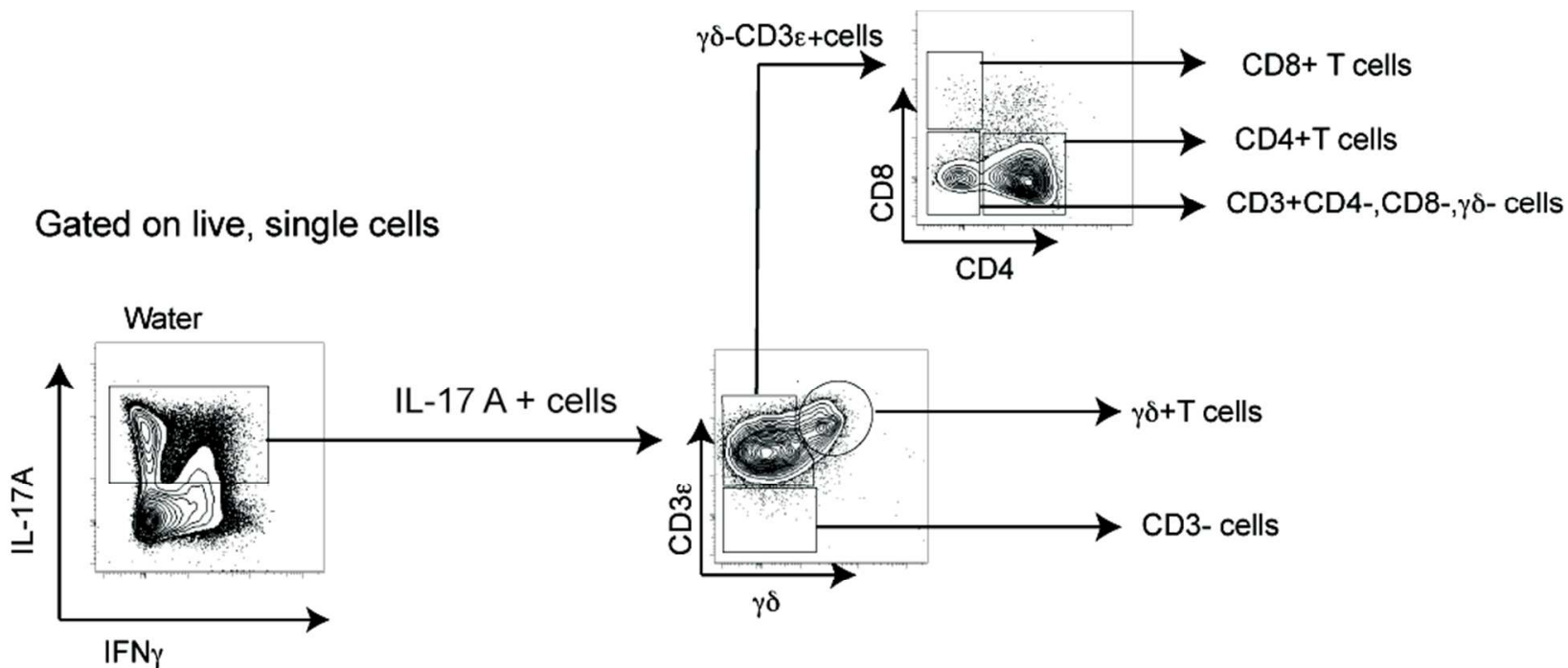

Figure E5: Gating Scheme for (A)macrophages and (B)IL-17 producing cells . 
A

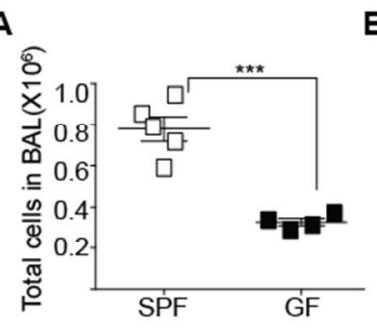

E

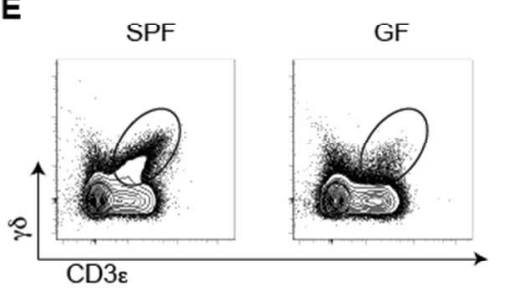

F

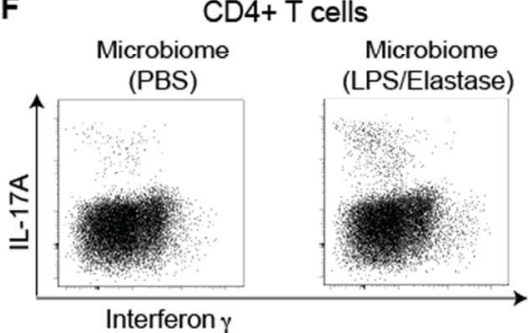

B

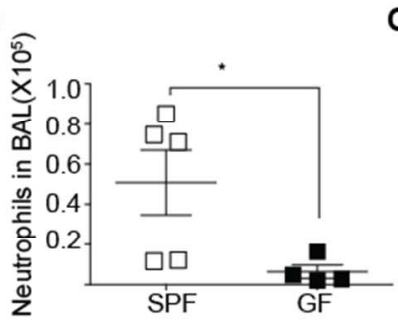

C

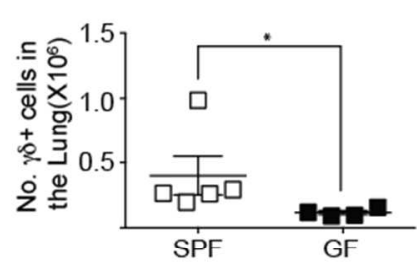

D

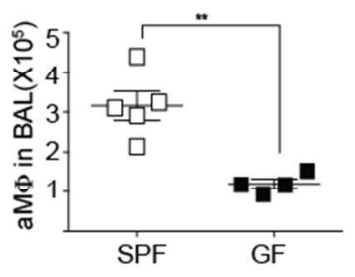

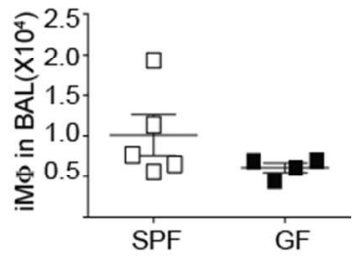

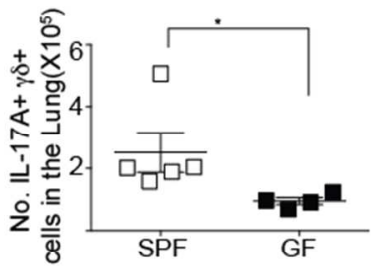

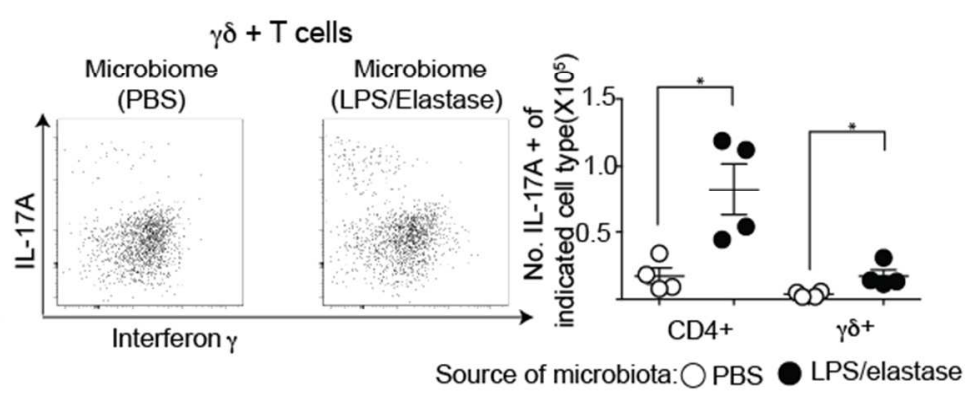

\section{Figure E6}




\section{Composition of IL-17A producing cells}
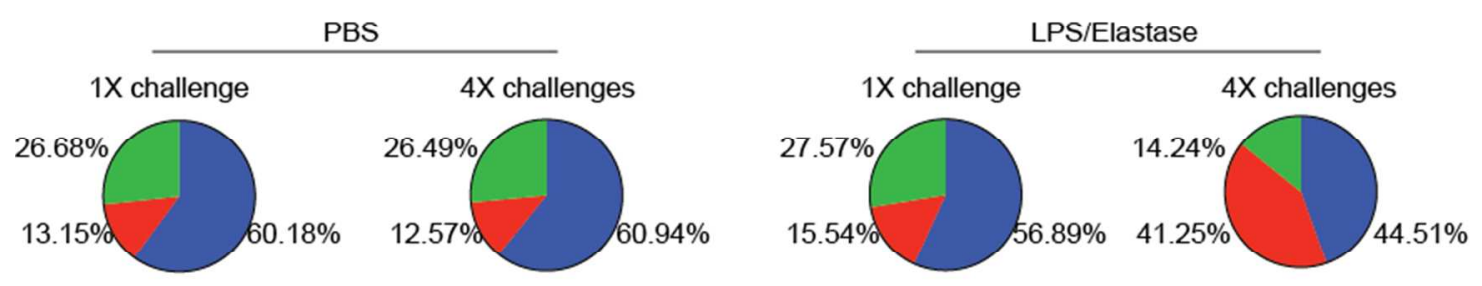

$\gamma \delta+T$ cells

CD4+ $\mathrm{T}$ cells

$\square$ Others

\section{Figure E7}

1. Saetta M, Shiner RJ, Angus GE, Kim WD, Wang NS, King M, Ghezzo H, Cosio MG.

Destructive index: A measurement of lung parenchymal destruction in smokers. The American review of respiratory disease 1985;131:764-769.

2. Thurlbeck WM. Measurement of pulmonary emphysema. The American review of respiratory disease 1967;95:752-764. 